\title{
EVALUATION OF SEDIMENT PROPERTIES IN THE LOWER HUTT AND PORIRUA AREAS BY MEANS OF CONE AND SEISMIC CONE PENETRATION TESTS
}

\author{
W. R. Stephenson'1, P. R. Barker²
}

\begin{abstract}
Cone and Seismic Cone Penetration Tests (CPT and SCPT) have been carried out at a total of 101 sites in the Porirua and Lower Hutt regions of New Zealand, initially (from 1975 to 1987) as government-funded publicgood science, and later as part of a multi-disciplinary microzoning project under contract to Wellington Regional Council.

The shear wave velocities and depths determined in the study were successfully used to predict small-signal resonant frequencies for two sediment-filled basins, and the inferred cohesions were used qualitatively to predict the importance of nonlinearities in limiting ground motion amplification.

The major results were the identification and shear wave characterisation of a surface layer (depth $12 \mathrm{~m}$, diameter $600 \mathrm{~m}$ ) of cohesive flexible sediment in the Porirua basin and a successful prediction of the associated basin resonant frequency, identification and shear wave characterisation of a thick surface layer (depth $30 \mathrm{~m}$, length $2 \mathrm{~km}$, width $500 \mathrm{~m}$ ) of cohesive flexible sediment in the Wainuiomata basin which explained an observed resonance, identification and shear wave characterisation of a wedge of flexible sediment, cohesive below and uncohesive above, in the lower part of the Hutt Valley, and identification of a pocket of flexible sediment in the Naenae area.
\end{abstract}

\section{INTRODUCTION}

\begin{abstract}
Although microzone effects during strong earthquakes have been commented on for many years, there is not yet a detailed consensus on how such effects arise, or how they should be predicted. This largely arises as a combination of our ignorance, the paucity of recorded data and the relative rarity of damaging earthquakes.
\end{abstract}

However there are broad agreements in some areas. Few workers would dispute the notion that thick layers of loose or soft water-saturated sediments are often associated with greatly increased damage, and those who do disagree would probably drop their objection for the case of a source several tens of kilometres away.

Again, most people would regard with deep suspicion an area which has repeatedly shown much more earthquake damage than nearby areas.

A soil site which consistently shows greater ground motion than nearby rock, for earthquakes and/or microtremors, becomes almost universally regarded as having an increased shaking hazard.

\footnotetext{
${ }^{1}$ Institute of Geological and Nuclear Sciences Ltd ${ }^{2}$ Landcare Research Ltd
}

But beyond these areas of general agreement lie areas of conflict. Is flexibility more important than layer thickness? How important are the effects of stress-strain nonlinearities? What is the role of cohesion? Why are soil/rock spectral ratios at given sites so variable from event to event? Why do onedimensional models underestimate duration? Do microtremors reflect the ability of soils to amplify ground motion, or merely the susceptibility of soils to excitation?

Such currently debated issues must be taken into account when any attempt is made to define microzones within an urban area. One approach, perhaps the only approach, is to measure small earthquakes at different sites, examine historical damage records and make appropriate geotechnical measurements. The final mapping of zones is then made on the basis of convergence of such measurements in the following way.

If past records show consistently high damage for an area, small earthquake surveys for the same area show high (possibly resonant) amplification, and a substantially thick layer (possibly with a sudden velocity discontinuity) of flexible subsurface material has been identified for the same area, a confident assignment to a hazardous zone can be made. At the other end of the scale, if damage records, small earthquake surveys and stiffness measurements all point to trivial ground effects, a nonhazardous zone is appropriate. Intermediate zones apply when intermediate damage, intermediate earthquake soil/rock spectral ratio and intermediate geotechnical conditions are encountered. In essence this describes the methodology adopted for defining microzones in the lower Hutt Valley and Porirua basin. 
The real zoning problems arise when some pieces of information conflict with others. In such cases (e.g. small earthquake resonant amplification is consistently seen but the regolith is a thin layer of stiff sand) a prudent act is to be pessimistic in zoning, but the only scientifically correct approach is to carry out further investigations.

The term regolith is used here in its original sense, now widely accepted by competent authorities [3], to denote the fragmented and unconsolidated material which covers the solid bedrock, irrespective of its origin.

Within this framework cone penetrometry has an important role to play because it provides estimates of key properties of the upper regolith, and it is regolith properties which control site response. Cone and seismic cone penetrometry offer costeffective ways of measuring shear wave velocity, assigning a soil engineering classification to each layer encountered and providing a relative indication of cohesion in the materials encountered. These measurements typically fill vital gaps in our knowledge of the regolith, because shear wave velocity controls the linear behaviour of the regolith material and cohesion is related to the shear strain at which nonlinear effects will become important. Neither of these parameters correlates strongly with anything seen on a conventional drill-log, and large changes in shear wave velocity can be caused by quite subtle variations in void ratio.

Given such a glowing testimonial to the virtues of cone penetrometry one may wonder why any other technique is needed. The answer comes in three parts. Firstly, though it is cost-effective, cone penetrometry is not cheap. Secondly, experience has shown that amplifications can occur where cone penetrometry has indicated stiff shallow material. And thirdly, insignificant but impenetrable inclusions of boulders or gravel can lead to inappropriate values for depth of flexible material. In other words a buried gravel lens, perhaps an old river feature, can be a false bottom

Nevertheless cone penetrometry must remain a cornerstone of microzoning studies in New Zealand.

\section{THE SEISMIC CPT PROBE (SCPT)}

Cone penetration tests have been part of geotechnical engineers' repertoire for some years, more particularly in Europe, and there has been a recent trend to use the cone as a convenient delivery system to deploy other sensors into the ground. A valuable outcome of this was a system whereby the cone had a miniature horizontally-sensing geophone built into it thus allowing the arrival of surface-generated shear waves to be measured at various depths [7]. Such an arrangement allows the shear wave velocity of the ground to be measured as a function of depth.

By 1988 New Zealand Soil Bureau (later to become DSIR Land Resources) had an operational version of the same system and was making striking measurements on unconsolidated sedimentary deposits [17],[19]. The current SCPT probe is shown in Fig. 1.

This CPT equipment is a Dutch mechanical cone [8] and consists of a steel cone with a tip angle of $60^{\circ}$ and a base area of $1000 \mathrm{~mm}^{2}$, attached to a sounding rod that can slide freely in an outer tube. A cylindrical friction sleeve of diameter $35 \mathrm{~mm}$ and area $14900 \mathrm{~mm}^{2}$ is attached by a linkage to the sounding rod and is located $200 \mathrm{~mm}$ above the cone. An hydraulic system measures the force applied to the sounding rods, which is initially the force required to drive the cone, and later both the cone and friction sleeve, through the soil. The probe is advanced at a nominal rate of $20 \mathrm{~mm} / \mathrm{sec}$, with cone and coneplus-sleeve readings being taken at $100 \mathrm{~mm}$ intervals.

Our seismic cone is attached to the standard CPT push rods and is thrust down the pre-existing hole made by the CPT cone.

The seismic probe has a miniature horizontal-sensing geophone mounted in a modified penetrometer cone. A preamplifier in the cone increases the signal amplitude and transmits it to an amplifier and data logging system at the ground surface via an electrical cable threaded through the penetrometer rods. The data logging system comprises a laptop personal computer with a 12 bit analogue-to-digital converter card. The data logging software utilises two input channels of the analog-to-digital converter and was written in assembler code to minimise timing delays. One channel is examined in a tight software loop to ascertain when the shear wave generator is struck by a hammer. The hammer blow generates a downward propagating horizontally polarised shear wave. After the hammer impact is detected, the second input channel digitises the arriving shear wave signal at one millisecond intervals. Each arrival sequence is stored as a disk file for later processing. The process of generating and recording shear waves is repeated at $0.5 \mathrm{~m}$ intervals from as far down as the cone can penetrate, to $0.5 \mathrm{~m}$ below the surface.

The data acquired can be stacked or filtered to enhance the signal. It is presented in the conventional seismic exploration format which allows reflections from changes in material to be seen as well as the direct arrivals (e.g. Fig. 16).

In the course of the investigations described in this paper the equipment evolved rapidly from a cumbersome system using a fast chart recorder with $100 \mathrm{~Hz}$ time marks, to the current system described above. The earlier versions were used for all the Hutt Valley measurements, for investigations in the Bay of Plenty [19], and for the Porirua work. The results from these areas are presented differently as the measurements were not recorded in digital form.

\section{APPLICATION OF PROBE RESULTS}

In the course of carrying out axisymmetric finite element modelling of the Porirua City area [18] it was found that the fundamental frequency of a typical basin can be deduced to a good approximation by applying infinite layer theory [12] to the material at the deepest part of the basin. The approximation fails only when the diameter of the basin is not large compared with its depth. A diameter to depth ratio of 10 introduces an error of $11 \%$ in the computed natural frequency for a cylindrical basin [16].

To assess the resonant properties of a local pocket or basin of flexible sediment it is necessary to determine the location and depth of the thickest accumulation of sediment, the shear wave velocity profile at that deepest part, and now nonlinear (in a shear stress-strain sense) the sediment is. The linearity of the sediment indicates how strong the ground shaking must be before resonant behaviour ceases. In general, cohesive sediments maintain linearity to far larger strains than cohesionless sediments. It is instructive to take the shear strain at which the shear modulus is halved as an indicative parameter and to look at the following representative cases: 


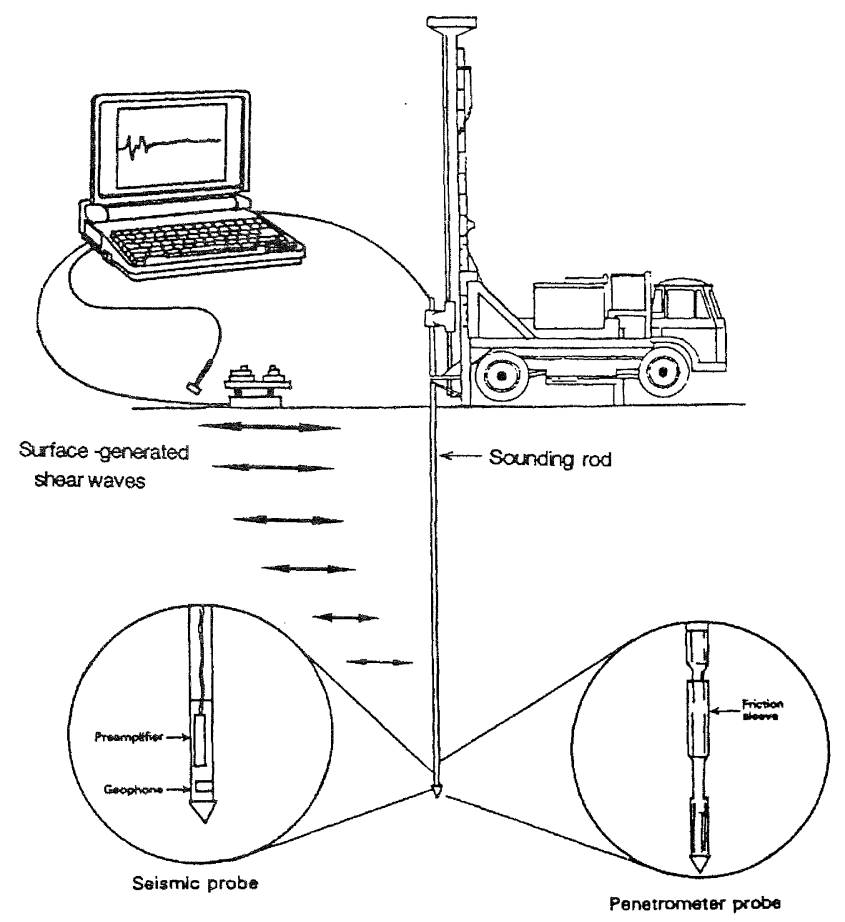

Fig. 1. Equipment used to obtain tip resistance and friction ratio (cone penetration test) and shearwave velocity (seismic cone penetration test) as functions of depth. Adapted from [18].

lacustrine clay, Mexico City

Bay Mud, San Francisco

silty sand to sandy silt, Taiwan
$1 \%$

$0.2 \%$

$0.02 \%$
[10]

[11]

[1]

Pender and Larkin [6] show the dramatic effect on response that can be induced by material of high plasticity index (caused in turn by a high proportion of clay sized particles, and correlated with high cohesion). During strong shaking, loadings to structures founded on plastic clays can be expected to be much higher than loadings to structures founded on sands.

The CPT probe provides measurements which describe two completely distinct aspects of soil behaviour. A sharp point being pushed into the ground (by a thin rod) is opposed by soil strength whereas a cylinder being pushed through a hole in the ground is opposed by the frictional forces between the cylinder and the ground. These frictional forces are related to the cohesion of the material - a soil which sticks together also sticks to the probe. These independent properties have been made the basis of soil engineering classification schemes by various researchers, and this study adopts that described by Searle [9], with the regions being defined as in Fig. 2. Such automatic schemes, based as they are on generalisations, must be used cautiously, either being field calibrated or used in a comparative sense in any given investigation.

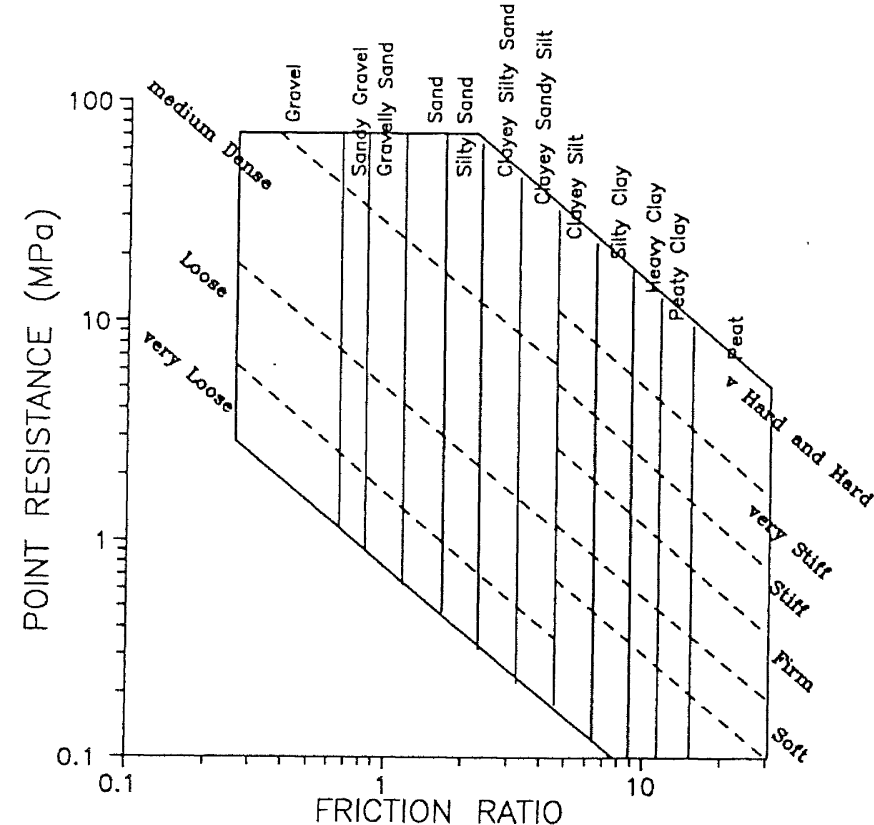

Fig. 2. Scheme adopted to assign soil engineering classifications on the basis on cone penetrometer tip and friction ratio values. See [8]. 
Because the CPT technique provides a good indication of the cohesion of, and hence the fraction of clay sized particles in sediments it clearly has promise as a means of obtaining the strain to which relatively linear behaviour may be expected. However, this promise will only be fully realised when a satisfactory database of earthquake-derived linearities and corresponding CPT tip and friction values for various sediments has been obtained.

SCPT probing can help to determine where the greatest thickness of flexible soil lies, the shear wave velocity profile and the amount of fine grained material, in a very cost-effective way. Trial probing with a standard Dutch cone soon reveals the extent and depth of the flexible material. By means of existing correlations [9] an idea of the fraction of fines, and hence the linearity, may be obtained. Finally, using the seismic cone at the known deepest point of the deposit, the shear wave velocity profile can rapidly be obtained.

None of the standard technologies of borelog data, cone penetration test, standard penetration test or seismic shear wave reflection/refraction can on their own give the complete range of relevant data that SCPT probing can, and none of them can compete with it on a basis of cost-effectiveness.

\section{PORIRUA}

The low-lying harbour setting of the Porirua town centre, to the north of Wellington (see Figs. 3 and 4), was identified as a location likely to comprise fine-grained sediments with few if any gravel layers and thus to be an area suited to characterisation by SCPT and CPT probing. Furthermore it is a centre of development, with harbour and near-shore swamp sediments (saturated sands, silts and peats) having been progressively reclaimed and built on over the years, and with more recent buildings tending to be multi-storied. Hence it is a region where evaluation of the seismic response of regolith materials by probing is both possible and very relevant.

SCPT probing and CPT probing was carried out to help evaluate the seismic hazard in the Porirua area. From general considerations of topography and stream gradient it was expected that any significant deposits of flexible sediment would be situated around Porirua harbour. To confirm this view, cone penetrometer tests (CPT) were carried out at the expected locations of maximum sediment depth in Tawa (at Coronation Park, Fig. 4, sites 1A and 1B) and Linden (at Kowhai Park, Fig. 4, site 1C). Depths to refusal were $1 \mathrm{~m}$ at Tawa and $2.8 \mathrm{~m}$

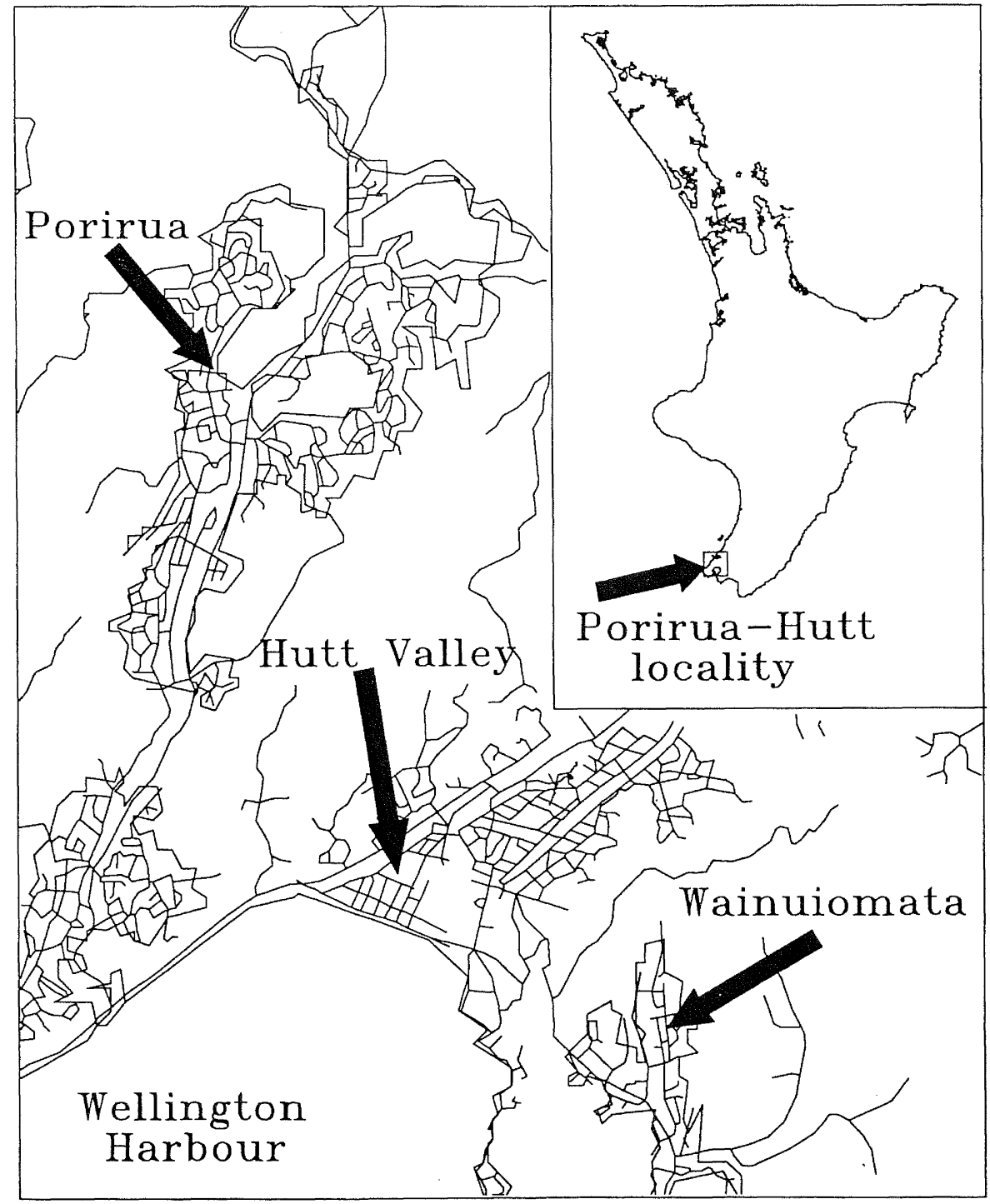

Fig. 3. Locality diagram of areas studied. 


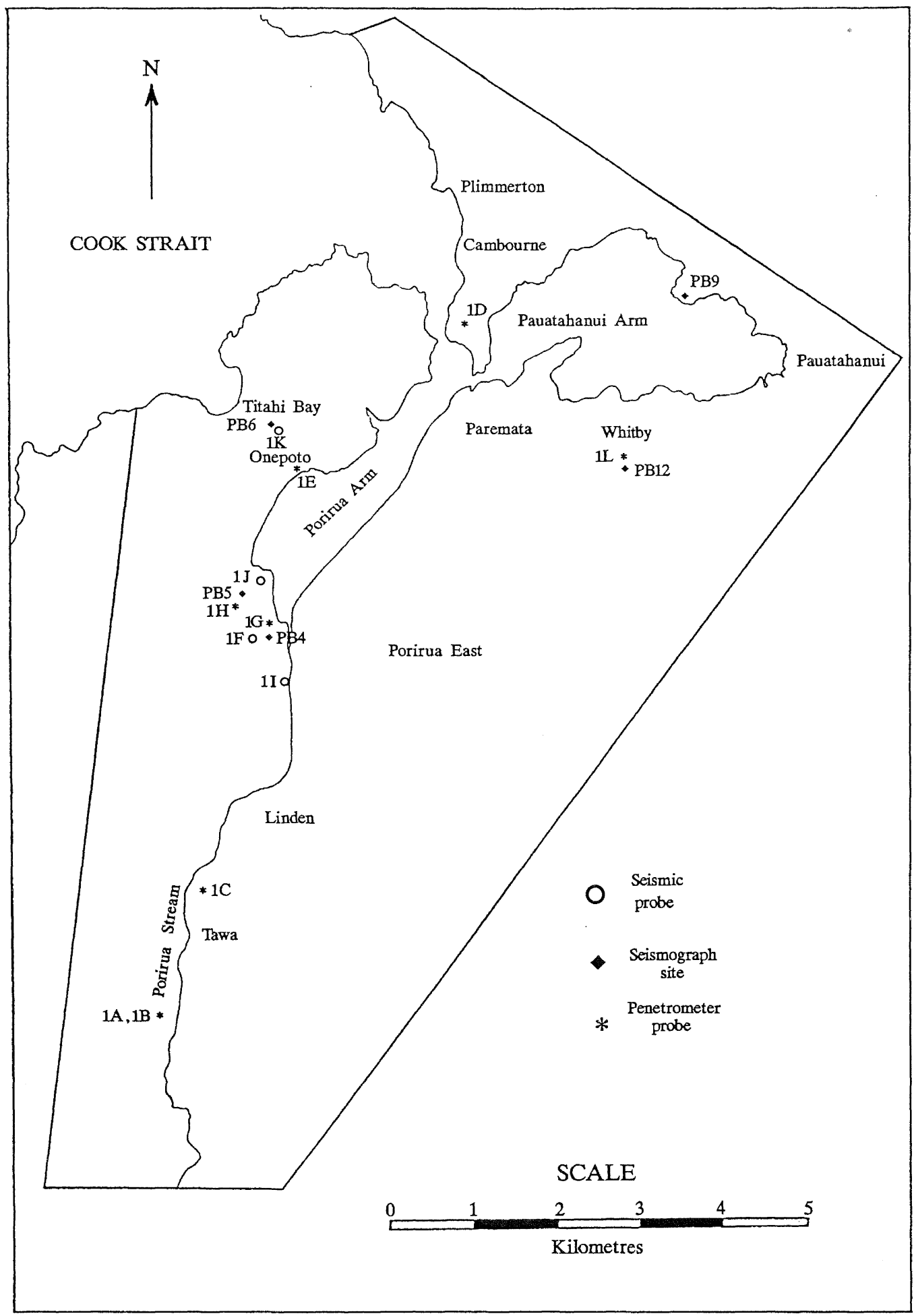

Fig. 4. Locations of penetrometer probes in Porirua. See table 1 for site details.

at Linden. The absence of significant depths of flexible sediment at these locations allowed attention to be focused on the harbour environs, where such material was expected.

A CPT probe was also attempted at Ngati Toa Domain, where flexible sediment was expected, but no penetration was possible beyond about $0.4 \mathrm{~m}$ due to the presence of tightly packed gravels.
Several CPT probes were made in the main Porirua basin area, and they showed that the maximum depth of sediment was located at Wi-Neera Drive. They were followed up by a series of SCPT probes.

The locations of CPT and SCPT sites are shown in Fig. 4, the grid references are given in Table 1, and the significant results obtained are graphically presented in Figs. 6 to 12 . In general the CPT results for the basin (Figs. 6 to 12) indicate a region of 
weak sedimentary material which increases in thickness and decreases in grain size in a northerly direction. This is consistent with estuarine deposition from the Porirua Stream. The finer silt and clay size minerals remain in suspension much longer and are carried north by the water flow from the Porirua Stream before they are deposited. This is confirmed from the borelog obtained at Wi-neera Drive, [2].

The seismic cone measurements at Wi-neera Drive (Fig. 11) and Porirua Recreation Centre (Fig. 7) showed a decrease in mean shear wave velocity as the fines content of the sediment increased. Such a result is expected. The value of 110 metres per second assigned to Wi-neera Drive is quite low, perhaps reflecting the small particle size and presumed low density. By way of comparison values of $75 \mathrm{~m} / \mathrm{s}$ have been recorded for the San Francisco bay muds, and values of $17 \mathrm{~m} / \mathrm{s}$ for swamp peats at Pukehou, Hawkes Bay [20].

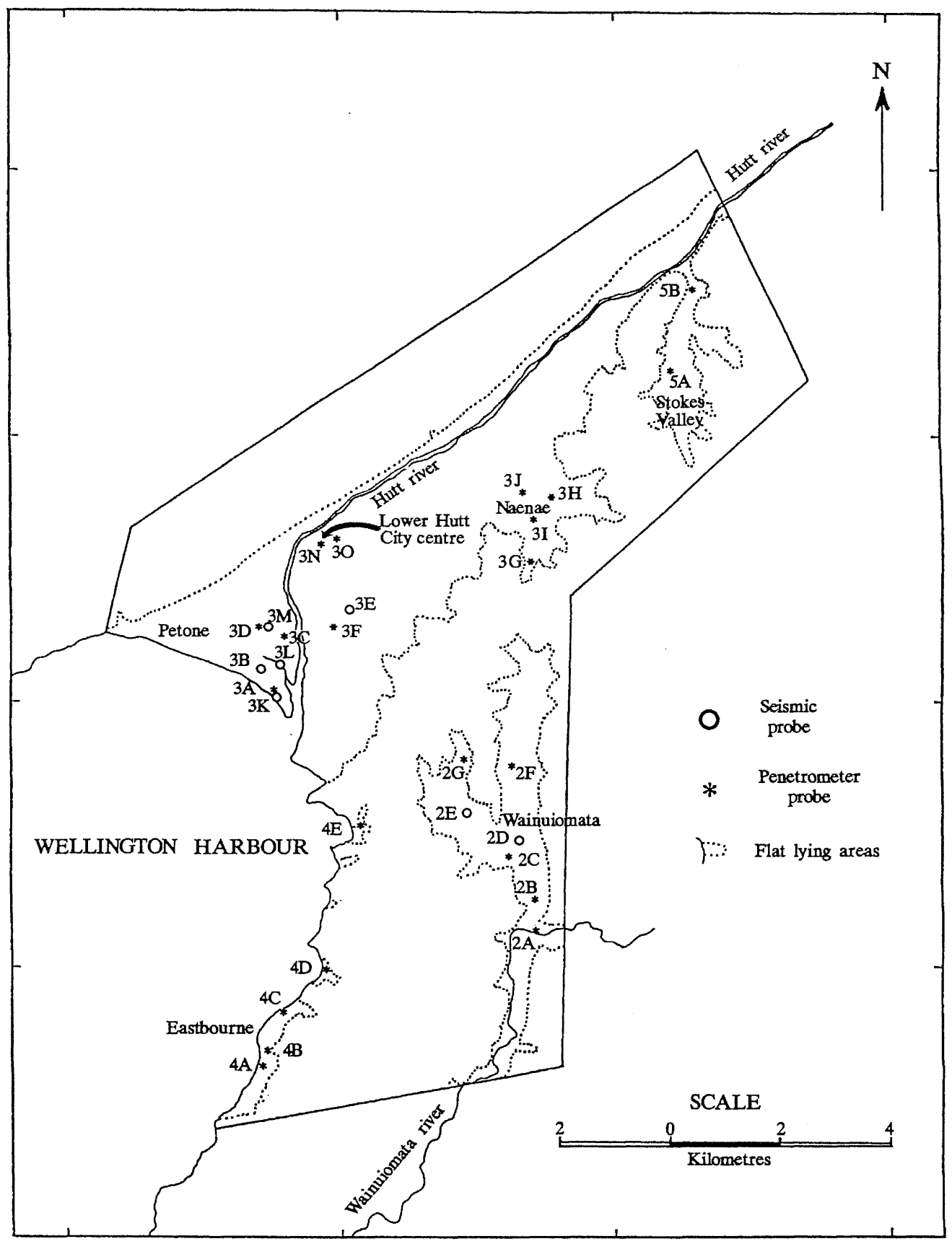

Fig. 5. Locations of penetrometer probes in Wainuiomata, Lower Hutt, Eastern Bays and Stokes Valley. See tables 2, 3, 4 and 5 for site details. 


\begin{tabular}{||lc|l||}
\hline \multicolumn{1}{|c|}{ SITE } & & NZMG REFERENCE \\
\hline Coronation Park 1 & 1A & NZMS 260 R27 632022 \\
\hline Coronation Park 2 & 1B & NZMS 260 R27 632022 \\
\hline Kowhai Park & 1C & NZMS 260 R27 637037 \\
\hline Ngati Toa Domain & 1D & NZMS 260 R27 668105 \\
\hline Onepoto Park & 1E & NZMS 260 R27 649087 \\
\hline Recreation Centre & 1F & NZMS 260 R27 643067 \\
\hline Semple St & 1G & NZMS 260 R27 645069 \\
\hline Elsdon Park & 1H & NZMS 260 R27 641071 \\
\hline Newall St & 1I & NZMS 260 R27 647062 \\
\hline Wi-Neera Drive & 1J & NZMS 260 R27 644074 \\
\hline Kura Park & 1K & NZMS 260 R27 646092 \\
\hline Discovery School & 1L & NZMS 260 R27 687089 \\
\hline \hline
\end{tabular}

Table 1. Locations of penetrometer sites in Porirua.

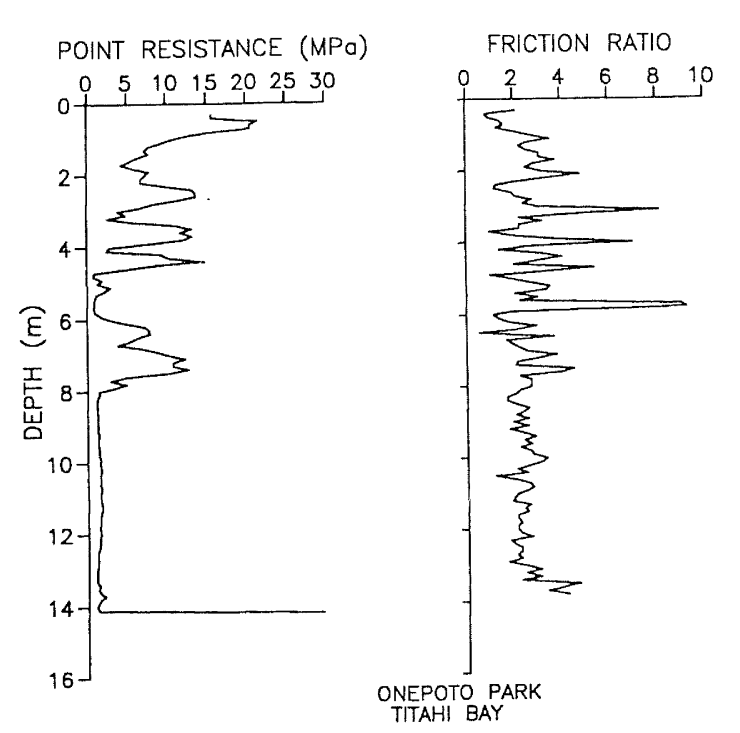

Fig. 6. Values of tip resistance and friction ratio as functions of depth at Onepoto Park, Porirua (site $1 \mathrm{E})$.

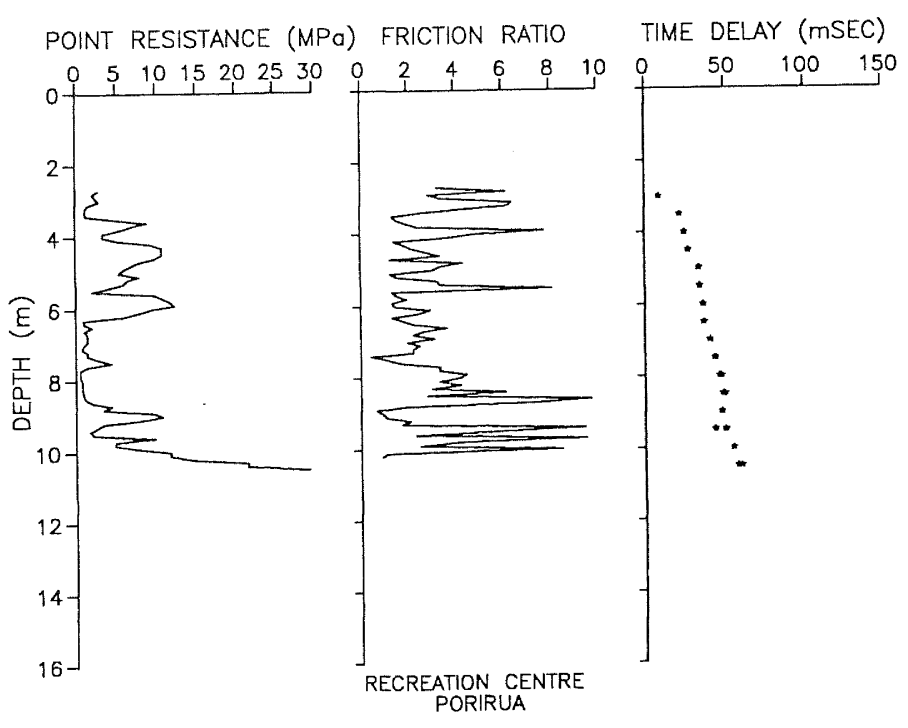

Fig. 7. Values of tip resistance, friction ratio and shear wave arrival time as functions of depth at Recreation Centre, Porirua (site 1F). 


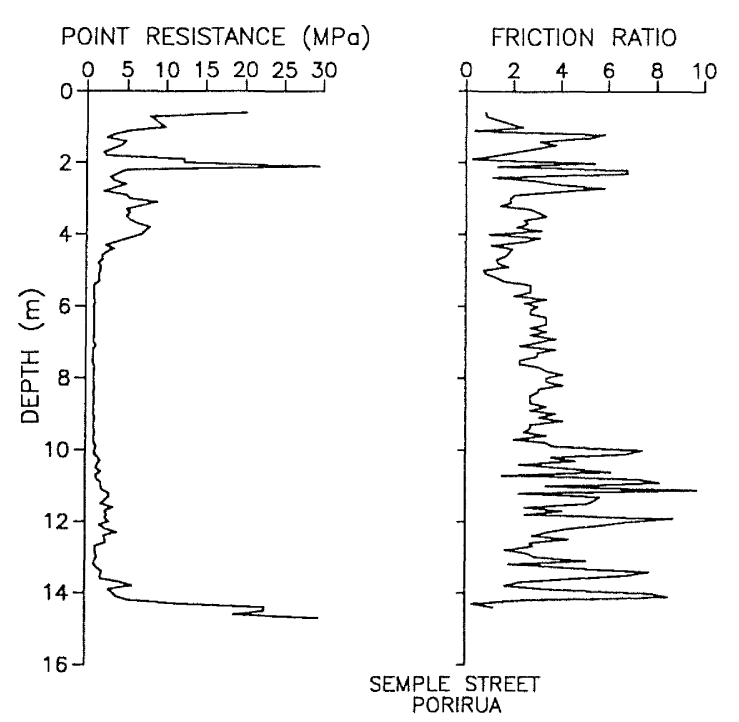

Fig. 8. Values of tip resistance and friction ratio as functions of depth at Semple St, Porirua (site $1 \mathrm{G)}$.

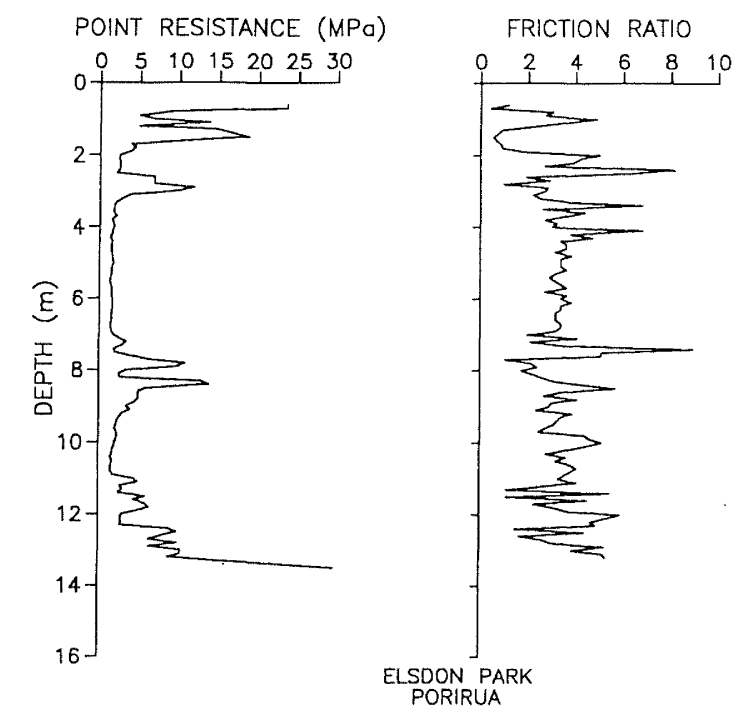

Fig. 9. Values of tip resistance and friction ratio as functions of depth at Elsdon Park, Porirua (site 1H).

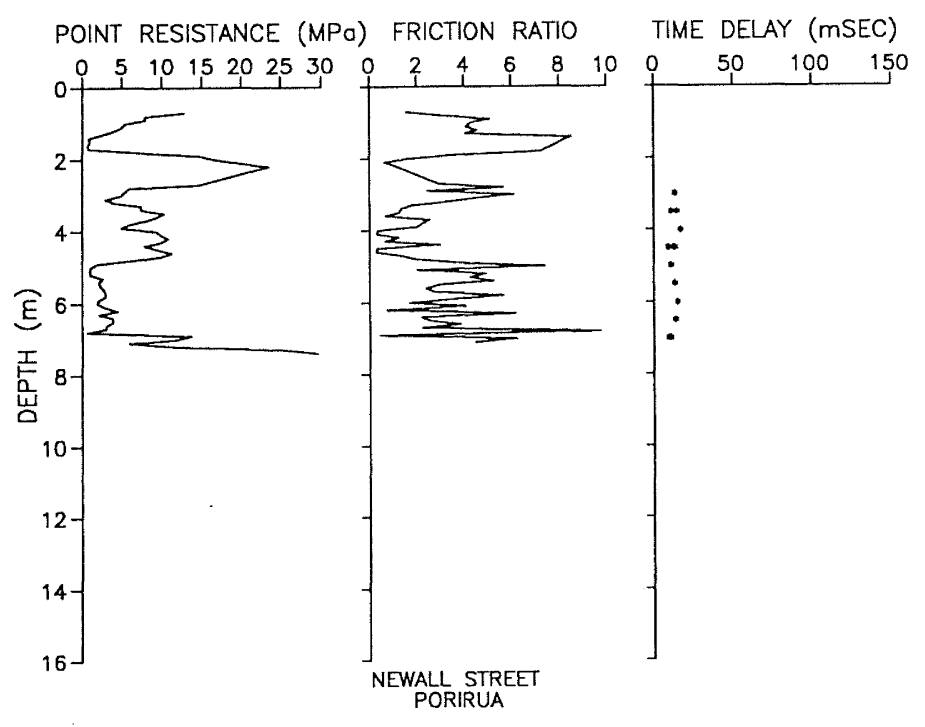

Fig. 10. Values of tip resistance, friction ratio and shear wave arrival time as functions of depth at Newall St, Porirua (site 11).

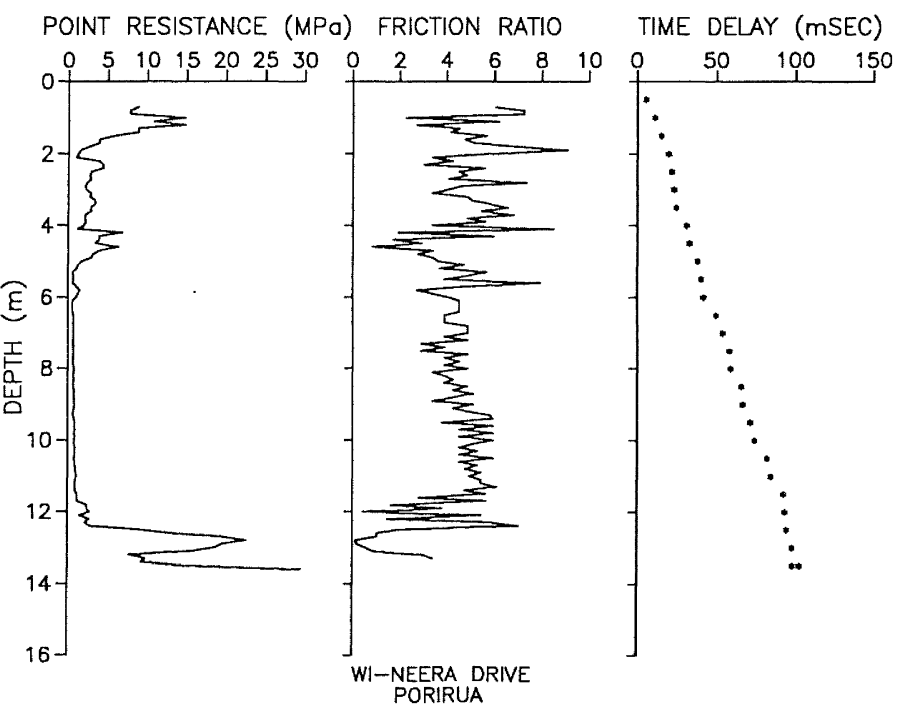

Fig. 11. Values of tip resistance, friction ratio and shear wave arrival time as functions of depth at WiNeera Drive, Porirua (site $1 \mathrm{~J}$ ). 


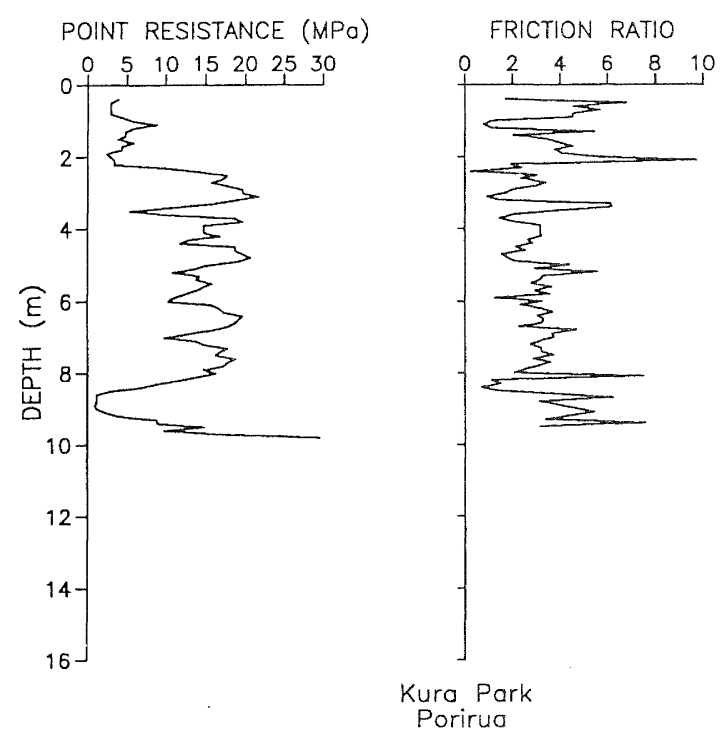

Fig. 12. Values of tip resistance and friction ratio as functions of depth at Kura Park, Porirua (site $1 \mathrm{~K})$.

The seismic cone results from Newall Street pose a problem which is unlikely to be easily resolved. All the first arrivals (Fig. 10) occurred with very little delay after the hammer impact on the shear wave generator. Such a result is not expected for shear waves in view of the CPT results. It is therefore likely that some site specific feature caused some conversion of shear waves to compressional waves, and that the first arrivals were of compressional waves (which travel very fast). The shear wave generator was located on a site (see Table 1) where $1.7 \mathrm{~m}$ of fill overlaid $1 \mathrm{~m}$ of gravels which were so tightly packed that the gravel layer had to be drilled. This stiff subsurface layer would attenuate shear waves more than it would compressional waves, and a sloping interface would cause conversion of shear waves to compressional waves. The generator always generates a small proportion of compressional waves, so either shear wave attenuation or shear wave to compressional wave conversion is responsible for first arrivals of compressional waves. In any event the arrival times of Fig. 10 must be disregarded.

This study characterised and mapped resonant sediment in the Porirua basin area. Later, Taber and Smith [23] reported on the measured resonant character of sites during small earthquakes for a wider area which included two sites on the resonant sediment, PB4 and PB5. There was a very close agreement between the predictions [24] and the observations [23] at these two sites.

However, an additional observation site, PB6, which was sited near to, but not on the area of mapped resonant sediment, also showed the resonant response predicted and observed for the sediment. A suspicion arose that the boundary to the resonant sediment had been incorrectly identified, so the boundary was checked by examining exposures and hand augering to shallow depths. It was concluded that the boundary had been correctly identified and that dune sands, perhaps with interdune peats, would be present at PB6.
Subsequent CPT and SCPT tests were carried out on Kura Park, at a site $30 \mathrm{~m}$ south of the PB6 sensor location. The CPT results are presented in Fig. 12. From these results it is seen that in the vicinity of PB6 there is some $10 \mathrm{~m}$ of sands with occasional thin peat beds. SCPT showed that the sands have a shear wave velocity of around $325 \mathrm{~m} / \mathrm{s}$.

Thus the PB6 result cannot be explained by a misidentification of the resonant sediment boundary, and some alternative explanation is needed. Two explanations are likely. First, it is possible, but unlikely, that $\mathrm{PB} 6$ is responding to a resonance which coincidentally has the same natural frequency as the resonant sediment. This could, for example, be due to a localised peat bed, a foundation resonance, a mode of the Titahi Bay-Porirua isthmus or radiated resonant signal (from a power pole for instance). Second, effects of the resonant sediment could penetrate laterally beyond the physical boundary into the somewhat less flexible but nevertheless compliant sands. This view is supported by the results from PB9 which show an attenuated $2 \mathrm{~Hz}$ resonance on firm material (stiffer than sand) close to the flexible materials of the Pauatahanui basin.

Although PB6 exhibits a resonance which on the whole is more dramatic than those at PB4 and PB5, the known resonant sediment sites, the fact that its response cannot be attributed to any physical cause means that it may not respond equally dramatically to a large distant earthquake. There is evidence [17], [22] that dramatic differences in damage due to earthquakes are caused by whole-basin modes being excited by the wave passage effects of large shallow distant earthquakes, so it becomes necessary to identify any resonance observed during other earthquakes with excitation of the same whole-basin modes before it is deemed hazardous.

The best way of establishing the significance of the PB6 site resonance would be to deploy a dense array of sensitive earthquake recorders in the locality at intervals of a few hundred metres, and to examine changes with distance in the height of the resonant peak.

Taber and Smith [23] also found an area of high amplification at their site P12 in Whitby, so a probe was undertaken at Discovery School, Whitby. This showed about $4 \mathrm{~m}$ of moderately dense silty sand overlying about $2 \mathrm{~m}$ of stiff clay and clayey silt. The shear wave velocity in these materials is unknown, and because the observed amplification was at the relatively high frequency of $5.5 \mathrm{~Hz}$ soil related amplification cannot be ruled out.

The overall response of the main Porirua basin was predicted by taking a velocity of $110 \mathrm{~m} / \mathrm{s}$ and a depth of $12 \mathrm{~m}$ at the deepest part of the basin, and modelling on the basis of a credible axisymmetric basin in resonance with circumferential motion. The modelling was based on a finite element computer program [18]. The natural frequency for the basin at low strain was deduced to be $2.5 \mathrm{~Hz}$.

Taber and Smith [23] found during micro earthquakes that several sites in the Porirua basin resonated at $2.4 \mathrm{~Hz}$, and McVerry [4] reported a similar observation for felt earthquakes recorded on strong motion seismographs. These measurements show that the prediction of a ground resonance was well borne out. 


\section{WAINUIOMATA}

The flat topography and drained swamp setting of parts of the Wainuiomata area make it a candidate for earthquake microzone effects. To determine the depth and extent of flexible sediments seven CPT and two SCPT tests were undertaken at the following sites: Rotary Park (Fig. 5, site 2A, CPT), behind 71 Main Road (Fig. 5, site 2B, CPT), corner of Queen and Fitzherbert Streets (Fig. 5, site 2C, CPT), next to Fire Station (Fig. 5, site 2D, CPT and SCPT), stream reserve next to Parkway College (Fig. 5, site 2E, CPT and SCPT), Mary Crowther Park (Fig. 5, site 2F, CPT) and Sun Valley School (Fig 5, site 2G, CPT).

The significant CPT and SCPT results are shown in Figs. 13 to 20. Grid references of the sites are given in Table 2 .

Significant thicknesses of flexible sediments were identified at all sites except Rotary Park. At Main Road (Fig. 13) there is $26 \mathrm{~m}$ of soft clayey silty sand and clayey silt overlying dense sand; at Queen Street (Fig. 14) there is $24 \mathrm{~m}$ of soft clayey silt overlying stiff-very stiff silty clay; at the Fire Station (Fig. 15) there is about $31 \mathrm{~m}$ of soft silty sand or sandy silt overlying stiff silty and hard silty clay; at Parkway College (Fig. 17) there is $29 \mathrm{~m}$ of soft clayey silt overlying (probably) dense sand and at Mary Crowther Park (Fig.19) there is about $4 \mathrm{~m}$ of soft silty sand over $4 \mathrm{~m}$ of moderately dense sand and gravel and stiff silty sand over, $17 \mathrm{~m}$ of soft clayey silt and clayey sandy silt. At $25 \mathrm{~m}$ depth there is a change to firm sandy silt and at about $29 \mathrm{~m}$ a further change to very firm clayey sandy silt. At the Sun Valley School (Fig. 20) there are numerous layers of weak and strong silty sands and gravelly sands to a depth of about 12 $\mathrm{m}$.

The thickness and nature of the flexible sediments is very similar from site to site and provides evidence that the Wainuiomata Valley north of the Wainuiomata River was once a lake.

At Rotary Park (site 2A) gravels were found at $0.8 \mathrm{~m}$ and were not able to be penetrated.

The seismic cone measurements at Parkway College (Fig. 18) and Wainuiomata fire station (Fig. 16) indicate considerable depths (around $30 \mathrm{~m}$ ) of extremely flexible sediments. The shear wave velocities recorded in the top $20 \mathrm{~m}$ were around $90 \mathrm{~m} / \mathrm{s}$, which may be compared with $75 \mathrm{~m} / \mathrm{s}$ for younger San Francisco bay muds.

These shear wave propagation results, when taken in conjunction with the cone penetration results of Figs. 17 and 15, allow the resonant character of the flexible sediments to be estimated. The situation is not as clear cut as was the case in Porirua because the flexible sediments occur in two layers. In Porirua there was only one layer. The upper Wainuiomata layer which has an average shear wave velocity of $90 \mathrm{~m} / \mathrm{s}$ and is $19 \mathrm{~m}$ thick may be expected to resonate at $1.2 \mathrm{~Hz}$, whereas the total depth of flexible material $(31 \mathrm{~m})$ has a shear wave propagation time of $0.277 \mathrm{sec}$ and will resonate at $0.9 \mathrm{~Hz}$. Resonances may be expected at both of these frequencies, but the $0.9 \mathrm{~Hz}$ one will be the more important because the velocity contrast at the $90 \mathrm{~m} / \mathrm{s}$ to $150 \mathrm{~m} / \mathrm{s}$ interface at $20 \mathrm{~m}$ is sufficient to reflect only $6 \%$ of downward propagating energy.

In the above assessment the values at Wainuiomata fire station have been taken as controlling the resonant frequency. As was the case in Porirua, whole-basin modes are expected, with the fundamental frequency being controlled by the shear wave velocity and depth at the deepest point (here taken as Wainuiomata fire station).

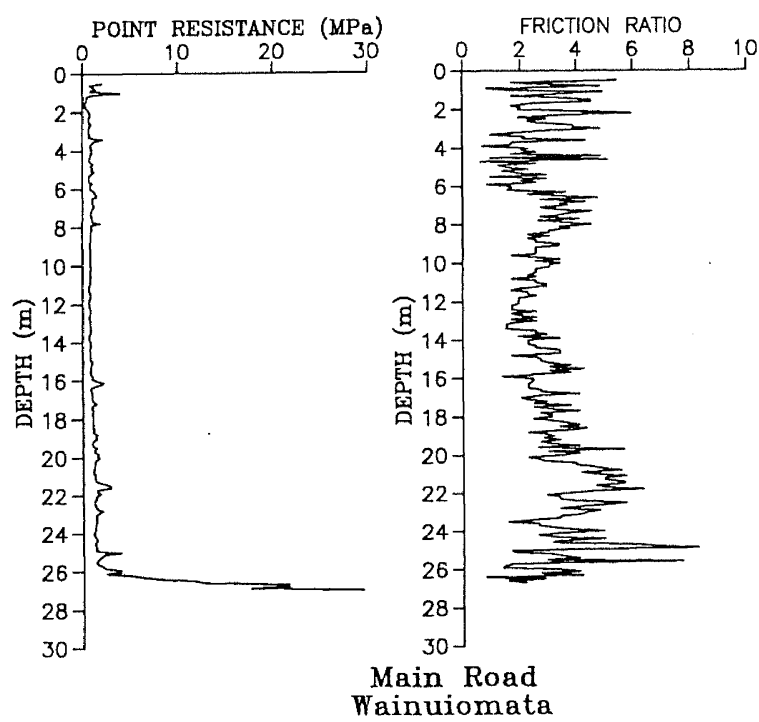

Fig. 13. Values of tip resistance and friction ratio as functions of depth at Main Road, Wainuiomata (site 2B).

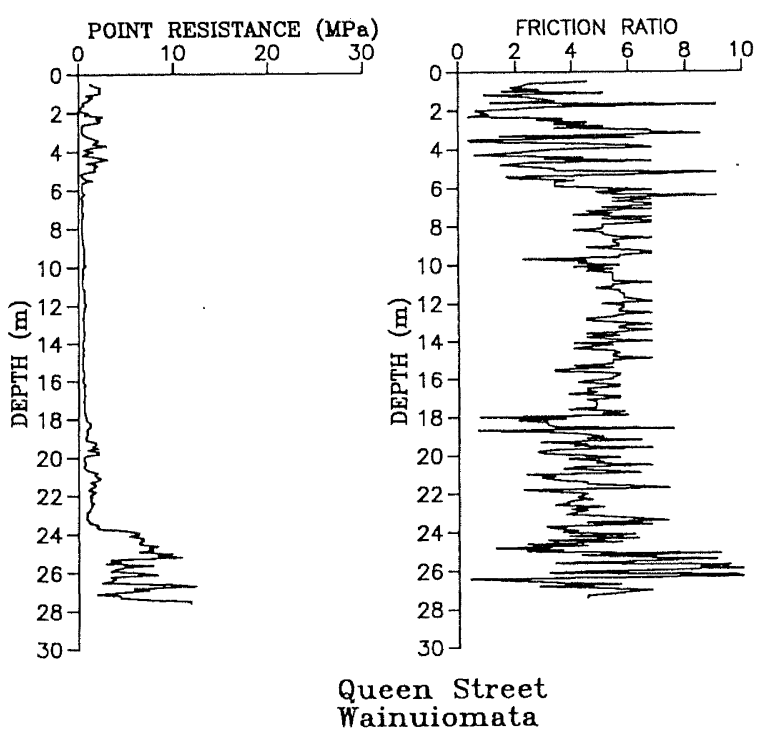

Fig. 14. Values of tip resistance and friction ratio as functions of depth at Queen St, Wainuiomata (site 2C). 


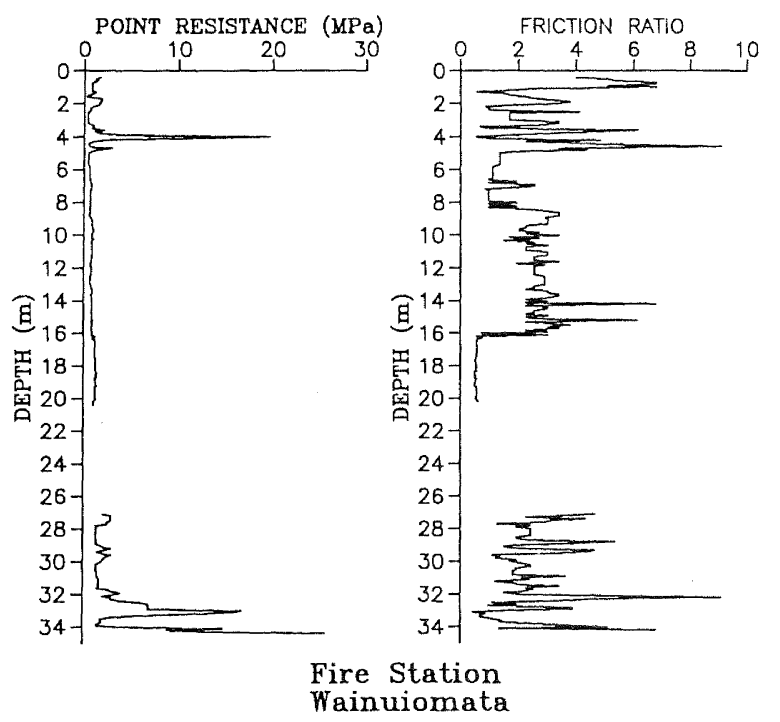

Fig. 15. Values of tip resistance and friction ratio as functions of depth at Fire Station, Wainuiomata (site 2D).

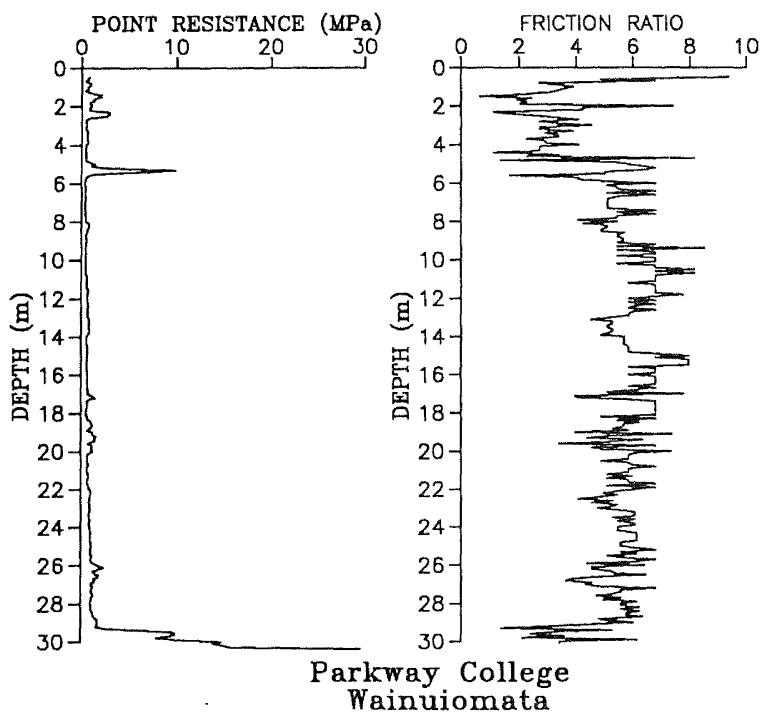

Fig. 17. Values of tip resistance and friction ratio as functions of depth at Parkway College, Wainuiomata (site 2E).

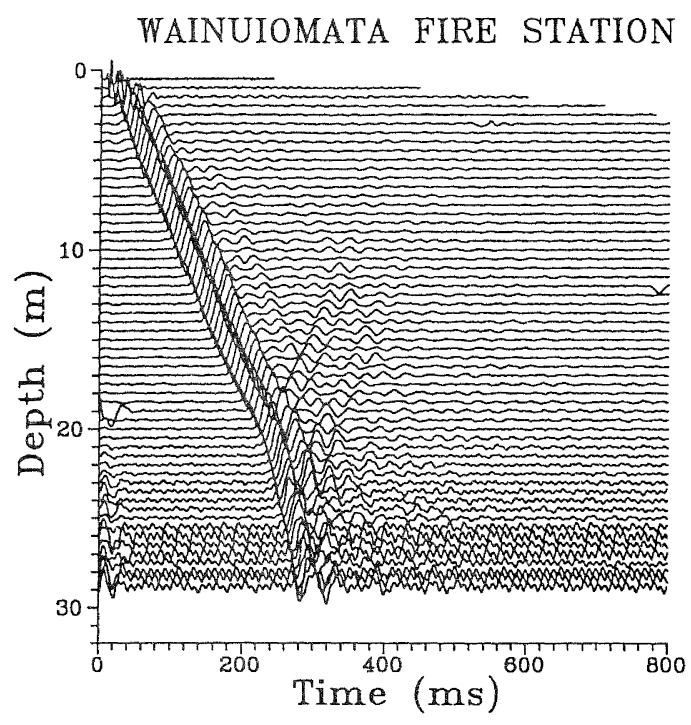

Fig. 16. Shear wave arrivals as functions of depth at Fire Station, Wainuiomata (site 2D).

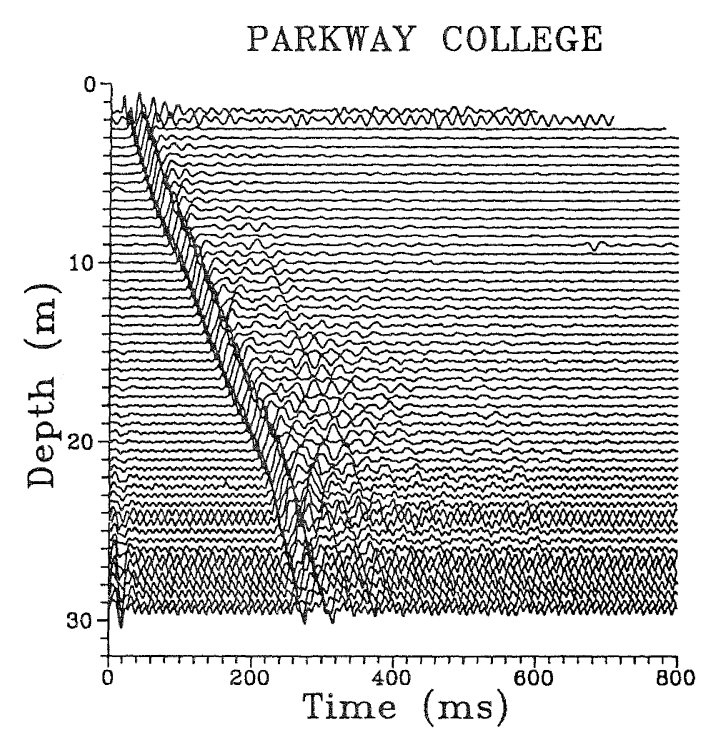

Fig. 18. Shear wave arrivals as functions of depth at Parkway College, Wainuiomata (site 2E). 


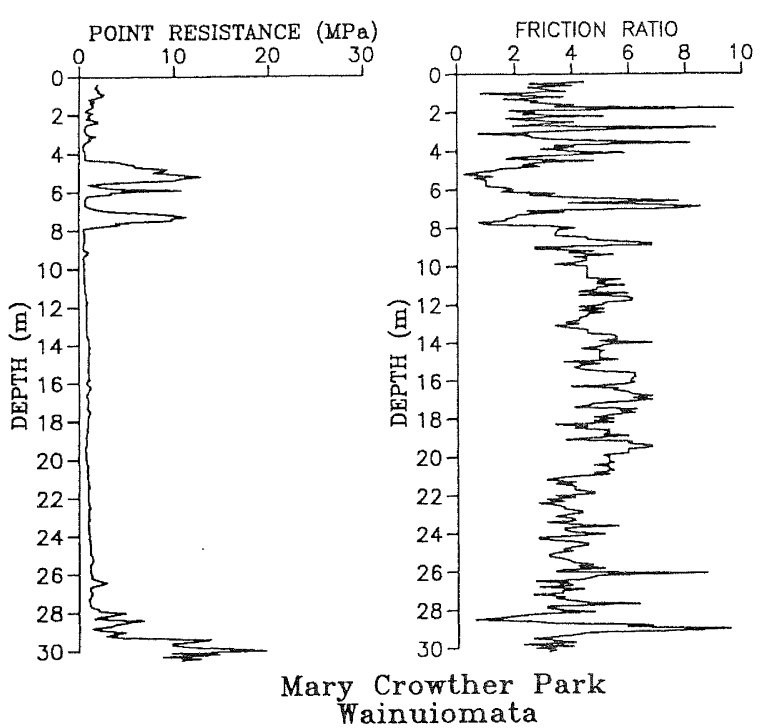

Fig. 19. Values of tip resistance and friction ratio as functions of depth at Mary Crowther Park, Wainuiomata (site 2F).

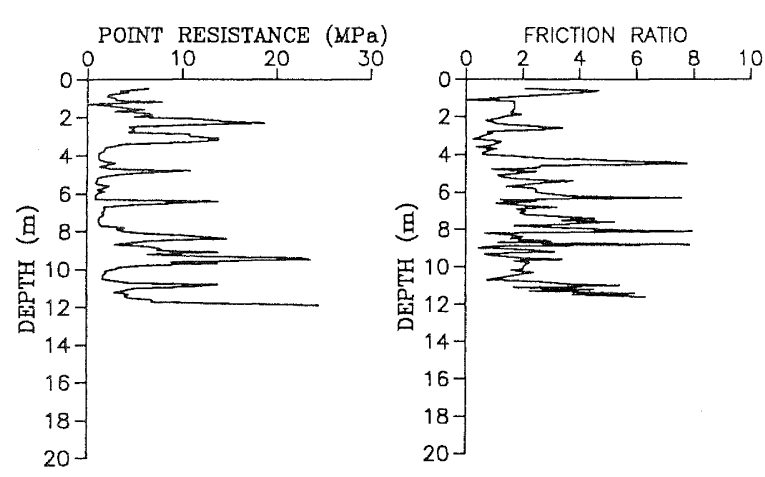

Sun Valley School Wainuiomata

Fig. 20. Values of tip resistance and friction ratio as functions of depth at Sun Valley School, Wainuiomata (site $2 \mathrm{G}$ ).

\begin{tabular}{|c|c|c|}
\hline \multicolumn{2}{|c|}{ SITE } & NZMG REFERENCE \\
\hline Rotary Park & $2 \mathrm{~A}$ & NZMS 260 R27 736907 \\
\hline Main Rd & $2 \mathrm{~B}$ & NZMS 260 R27 736913 \\
\hline Queen St & $2 \mathrm{C}$ & NZMS 260 R27 731921 \\
\hline Fire Station & $2 \mathrm{D}$ & NZMS 260 R27 733924 \\
\hline Parkway College & $2 \mathrm{E}$ & NZMS 260 R27 723929 \\
\hline Mary Crowther Park & $2 \mathrm{~F}$ & NZMS 260 R27 732938 \\
\hline Sun Valley School & $2 \mathrm{G}$ & NZMS 260 R27 723939 \\
\hline
\end{tabular}

Table 2. Locations of penetrometer sites in Wainuiomata.

Issues related to linearity of the stress-strain characteristics of sediments are pertinent to the response of the sediment to earthquakes. It is clear that a non-linear response has occurred if liquefaction or ground damage is observed, but in the absence of such gross indications, field and laboratory tests must be used to establish whether the material has entered a non-linear regime. Published data indicates a wide range of non-linear behaviour. A general pattern seems to be emerging that high clay content can make sedimentary materials behave in a more linear fashion than previously thought possible. The fact that the Wainuiomata material is very fine grained and shows no change of shear wave velocity with confinement stress (depth), suggests that it would be unwise to dismiss high earthquake intensities on the basis that a non-linear response will occur at relatively low ground strains. Behaviour approaching a Mexico City situation cannot be ruled out.
We consider that for strain values where the shear modulus falls to half of its low strain value, high material damping and hysteretic effects will make resonant amplification less important. Accordingly our range for the resonant period at Wainuiomata is 0.8 to 1.4 seconds. The lower value is the low strain measured period for the top layer and the upper value the low strain measured period for both layers increased by $25 \%$ to allow for non-linear response.

Taber and Smith [23] identified a peak of $1 \mathrm{~Hz}$ in the spectral ratio of this site compared to a bedrock reference site, during micro earthquakes, and Sritharan and McVerry [13] reported an enhanced response of this site at $1.2 \mathrm{sec}(0.8 \mathrm{sec})$. The agreement with the low strain value of $0.9 \mathrm{~Hz}$ predicted for both layers is pleasing. 


\section{HUTT VALLEY}

In 1975 DSIR Soil Bureau commenced a program of CPT testing in the Hutt Valley area, motivated by the surge of interest in microzoning that dated from observations of clear microzone effects from the 1967 Caracas earthquake. SCPT had not then been invented, so all the work was done with a Begemann (Dutch) cone. The object was to map the depth to gravels south of the Taita gorge, and the operators were instructed to push the probe until it refused to advance under a 3 tonne load. A total of 77 probes were made between the Taita gorge and the Petone waterfront. The majority of these probes encountered near-surface gravels at quite shallow depths and provided information which is of dubious value in a microzoning context because the layers involved may be comparatively thin with additional flexible material beneath.

Twelve of these probes reached depths of over 5 metres, and the results from them are given in this paper. The remaining 65 probes may contain results of general geotechnical interest.

The sites of the twelve deeper probes are shown in Fig. 5, and their grid references given in Table 3. Of these twelve probes, six had readings taken at $100 \mathrm{~mm}$ intervals and the rest at $200 \mathrm{~mm}$ intervals. The consequences of economising on readings are evident on examination of Figs. 21 to 32, where it is seen that the $200 \mathrm{~mm}$ reading interval gives friction ratios that are hard to assess when the material properties vary rapidly. The explanation is that the cone must always advance as readings are taken, and the sleeve reading is the difference between cone alone, and cone plus sleeve readings. Rapidly varying properties invalidate the assumption of constant cone force, but taking readings at shorter intervals provides more data points so that a trend may be extracted from the noise.

The individual sites may be summarised as follows. McEwan Park (Fig. 21) has $12.1 \mathrm{~m}$ of material which varies downward from sand to silty sand, but the probe was not taken to refusal. Schofield St (Fig. 22) has $22.4 \mathrm{~m}$ of material, basically in two layers, sand above and silty clay below. At Shandon Golf Course (site 2) (Fig. 23) there is $6 \mathrm{~m}$ of predominantly sandy material with two peat layers near the surface, while at the nearby Wilford School (Fig. 24) $10 \mathrm{~m}$ of sandy material becoming finer downwards, overlies $5 \mathrm{~m}$ of firm clayey silt which becomes coarser downwards. At the comer of Myrtle St and Knights Rd (Fig. 25) $2.5 \mathrm{~m}$ of soft fine grained material overlies sand to a total depth of $6 \mathrm{~m}$. Eastern Hutt School (Fig. 26) has $7 \mathrm{~m}$ of soft fine grained material over $7 \mathrm{~m}$ of firmer, but still fine grained material. At Massey and Miro Sts (Fig. 27) $2 \mathrm{~m}$ of fine grained material overlies $10 \mathrm{~m}$ of firmer, coarser grained material. Moera Overbridge (Fig. 28) has $1.5 \mathrm{~m}$ of fine grained material overlying $4 \mathrm{~m}$ of coarser grained material. The probe at Naenae Park (Fig. 29) revealed $14 \mathrm{~m}$ of relatively loose somewhat coarse grained material, while at nearby St Bernadette's School (Fig. 30) $12 \mathrm{~m}$ of material was easily penetrated, but its nature is hard to determine because of the $200 \mathrm{~mm}$ interval used and the highly variable tip resistance. Judd Crescent (Fig. 31) and Mildenhall Park (Fig. 32) both had around $7 \mathrm{~m}$ of easily penetrated material, with the friction ratios once again hard to interpret.

The move by DSIR Land Resources to making SCPT measurements was a response to a long standing lower Hutt Valley problem. Stephenson [17] had previously studied resonant effects in the Hutt Valley and shear wave velocity data

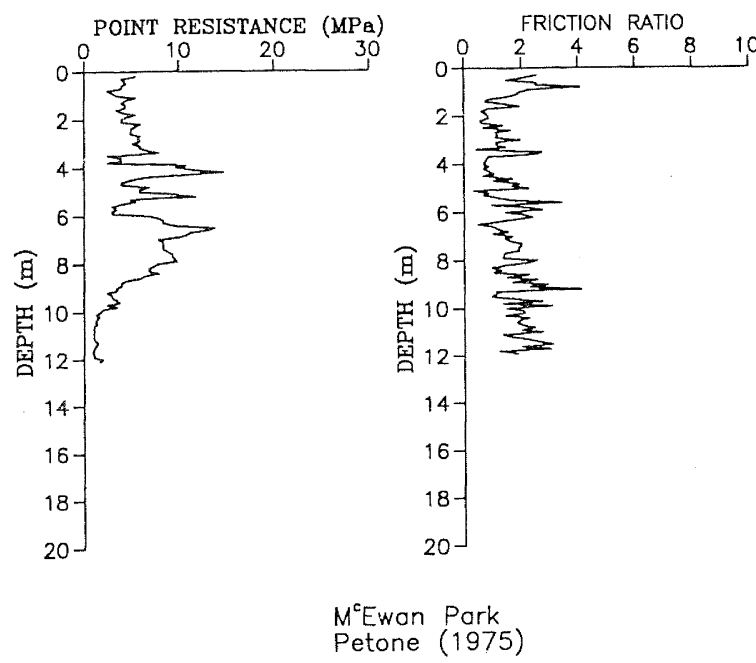

Fig. 21. Values of tip resistance and friction ratio as functions of depth at McEwan Park, lower Hutt Valley, 1975 (site 3A).

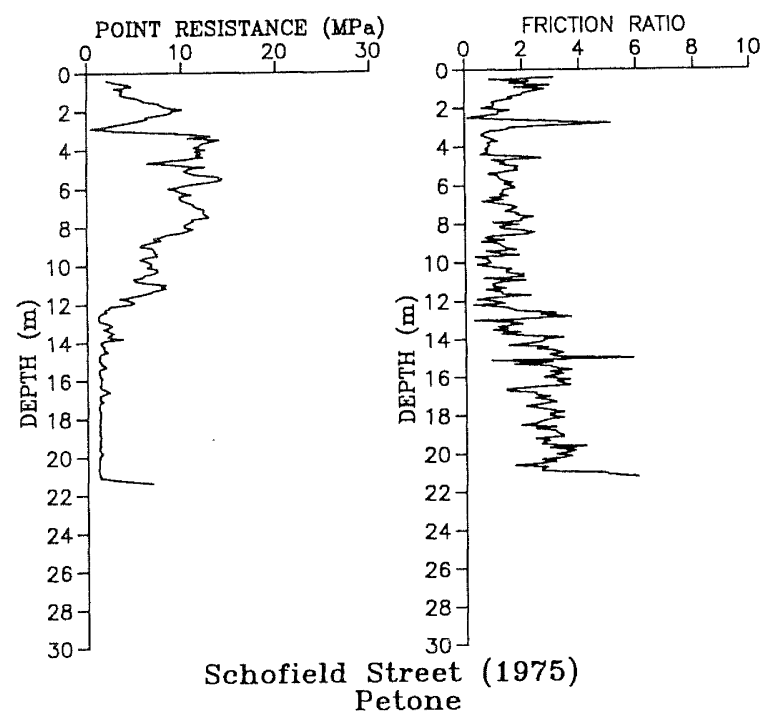

Fig. 22. Values of tip resistance and friction ratio as functions of depth at Schofield St play area, lower Hutt Valley, 1975 (site 3B).

was needed to assess these effects properly. The probe was initially used at a site (Schofield St play area) near the Hutt River estuary bridge because it was known from one of the early CPT probes there that encountering obstacles above the bottom of the flexible material was unlikely. The results are shown in Fig. 34, which provides a clear lesson that the shear wave velocity is only loosely related to the cone resistance. The shear wave velocity is nearly constant with depth (at $175 \mathrm{~m} / \mathrm{s}$ ) whereas the cone resistance, an index of strength, varies by an order of magnitude in the same interval. 


\begin{tabular}{|c|c|c|}
\hline SITE & & NZMG REFERENCE \\
\hline McEwan Park (early) & $3 \mathrm{~A}$ & NZMS 260 R27 688952 \\
\hline Schofield St play area & $3 \mathrm{~B}$ & NZMS 260 R27 685957 \\
\hline Shandon Golf Course (site 2) & $3 \mathrm{C}$ & NZMS 260 R27 690962 \\
\hline Wilford School & $3 \mathrm{D}$ & NZMS 260 R27 686964 \\
\hline Miro and Massey Streets & $3 \mathrm{E}$ & NZMS 260 R27 702967 \\
\hline Moera Overbridge & $3 \mathrm{~F}$ & NZMS 260 R27 699964 \\
\hline Naenae Park & $3 \mathrm{G}$ & NZMS 260 R27 736984 \\
\hline St Bernadette's School & $3 \mathrm{H}$ & NZMS 260 R27 739988 \\
\hline Judd Crescent & $3 I$ & NZMS 260 R27 735976 \\
\hline Walter Mildenhall Park & $3 \mathrm{~J}$ & NZMS 260 R27 734989 \\
\hline McEwan Park, SCPT & $3 \mathrm{~K}$ & NZMS 260 R27 688951 \\
\hline Shandon Golf Course, SCPT & $3 \mathrm{~L}$ & NZMS 260 R27 689957 \\
\hline Te Mome Stream & $3 \mathrm{M}$ & NZMS 260 R27 687964 \\
\hline Myrtle St. and Knights Rd. & $3 \mathrm{~N}$ & NZMS 260 R27 698978 \\
\hline Eastern Hutt School & 30 & NZMS 260 R27 703982 \\
\hline
\end{tabular}

Table 3. Locations of penetrometer sites in the Hutt Valley.

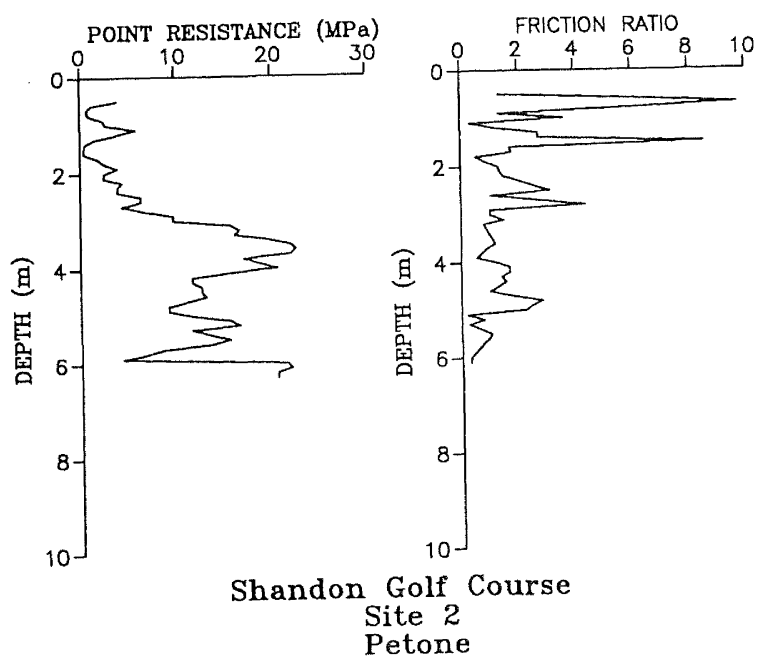

Fig. 23. Values of tip resistance and friction ratio as functions of depth at "Shandon Golf Course (site 2)", lower Hutt Valley (site 3C).

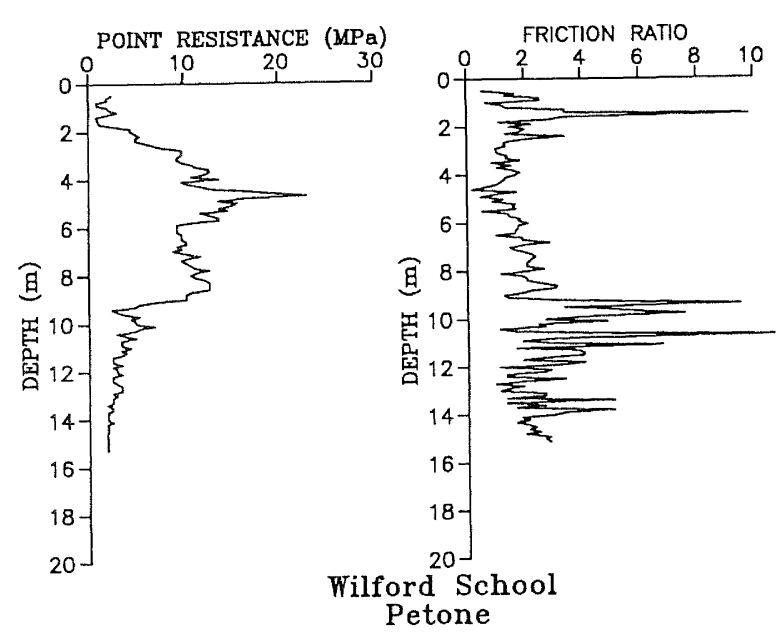

Fig. 24. Values of tip resistance and friction ratio as functions of depth at Wilford School, lower Hutt Valley (site 3D). 


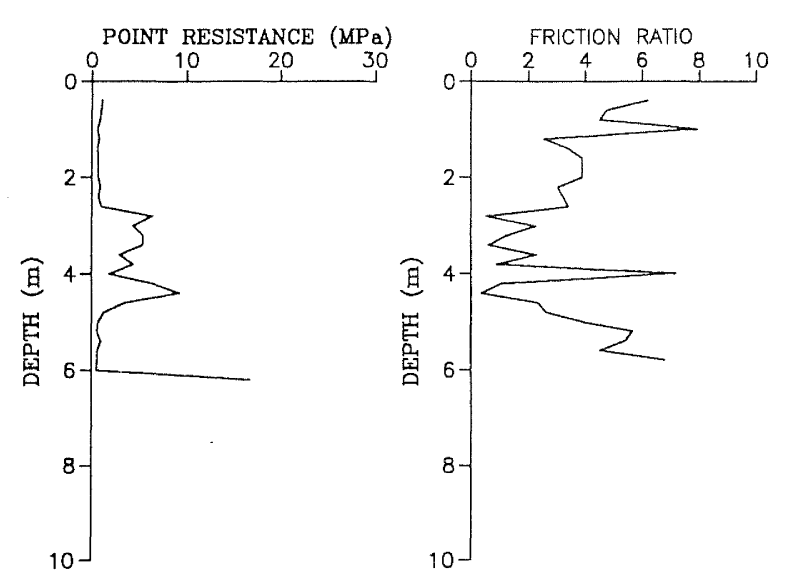

Cnr Myrtle \& Knights

Fig. 25. Values of tip resistance and friction ratio as functions of depth at corner of Myrtle St and Knights Rd, lower Hutt Valley (site $3 \mathrm{~N}$ ).

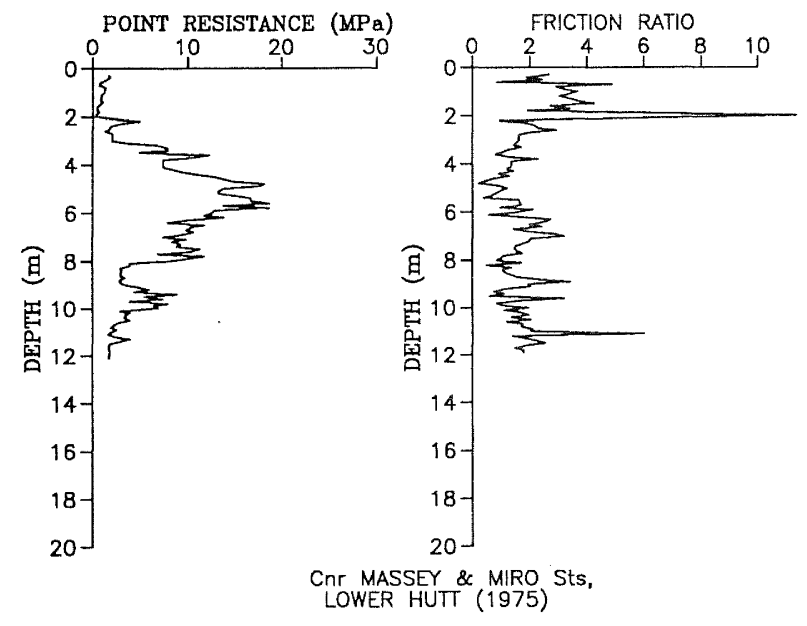

Fig. 27. Values of tip resistance and friction ratio as functions of depth at corner of Massey St and Miro St, lower Hutt Valley (site 3E).

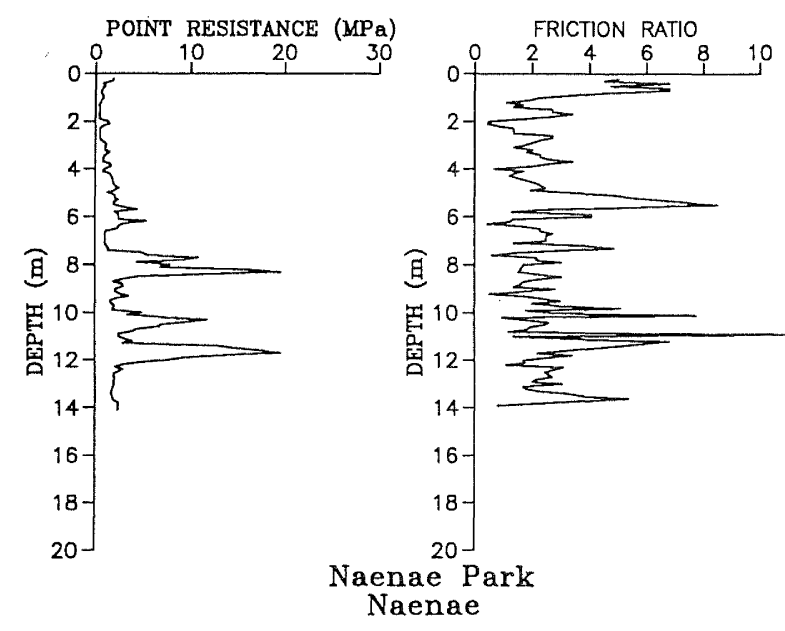

Fig. 29. Values of tip resistance and friction ratio as functions of depth at Naenae Park, lower Hutt Valley (site $3 \mathrm{G}$ ).

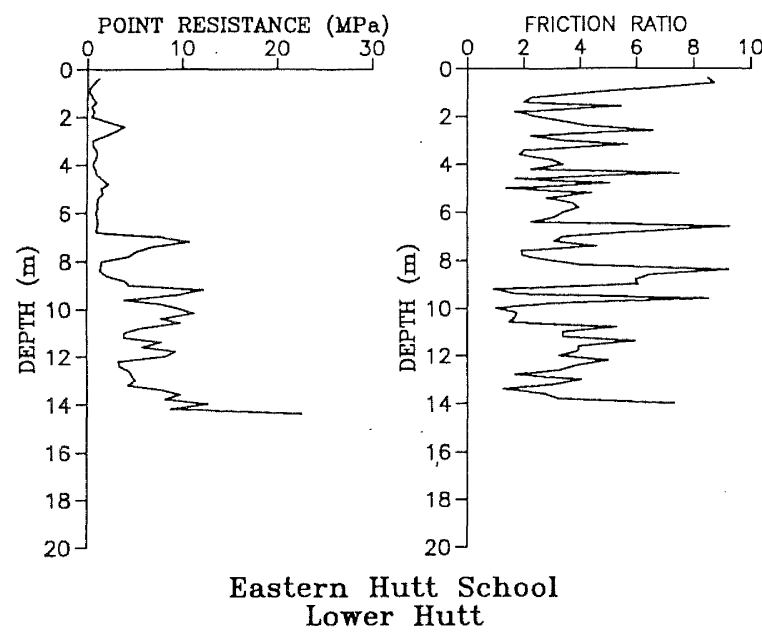

Fig. 26. Values of tip resistance and friction ratio as functions of depth at Eastern Hutt School, lower Hutt Valley (site 30).

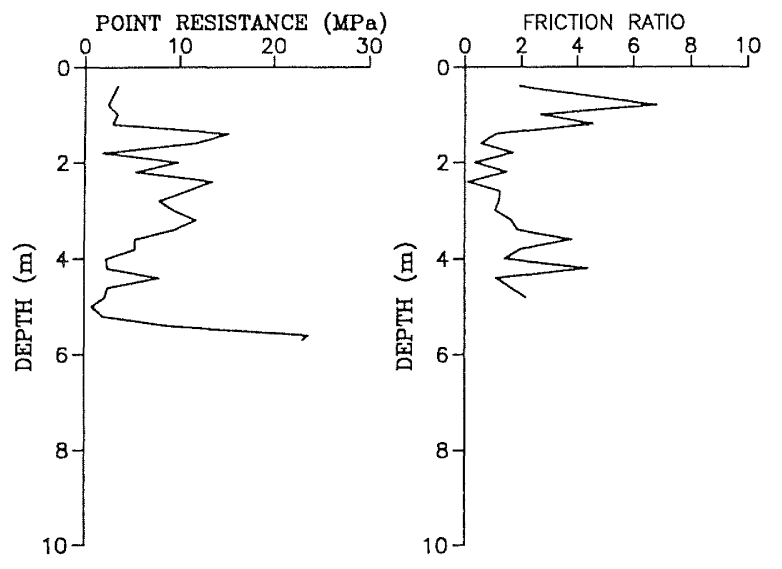

Moera Overbridge

Moera

Fig. 28. Values of tip resistance and friction ratio as functions of depth at Moera Overbridge, lower Hutt Valley (site 3F).

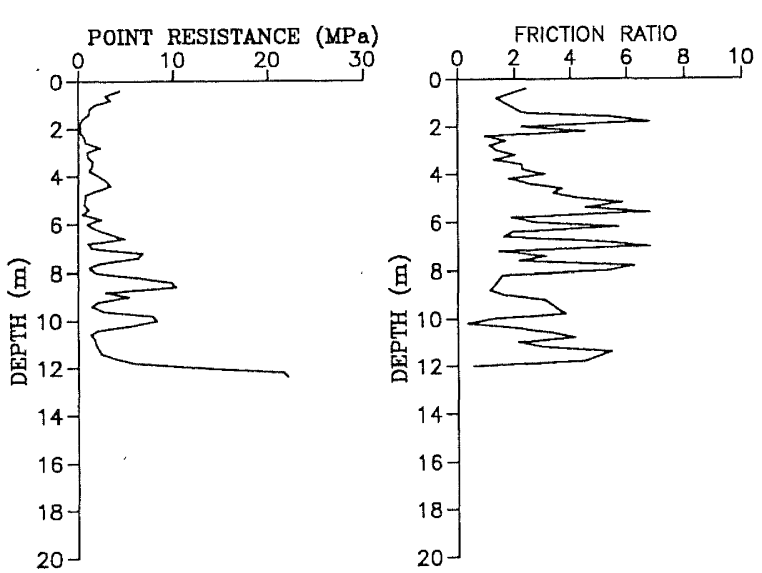

St. Bernadette School

Naenae

Fig. 30. Values of tip resistance and friction ratio as functions of depth at St Bernadettes School, lower Hutt Valley (site 3H). 


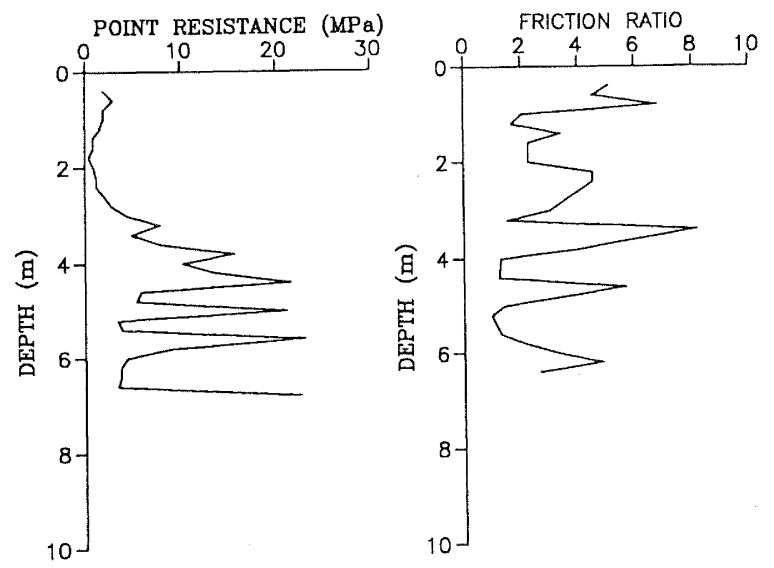

Judd Cresent Reserve

Naenae

Fig. 31. Values of tip resistance and friction ratio as functions of depth at Judd Cres, lower Hutt Valley (site 3I).

The measured shear wave velocity of $175 \mathrm{~m} / \mathrm{s}$ and $22.4 \mathrm{~m}$ depth of flexible sediments lead to an assigned resonator frequency of $1.95 \mathrm{~Hz}$ and Stephenson [17] shows that the 1968 Cook Strait earthquake excited a Hutt Valley resonator of natural frequency of $2.15 \mathrm{~Hz}$. While the probing appears to have accounted for this particular resonance the agreement must be regarded as fortuitous because it is evident from [14] that the Hutt Valley situation is complex, with several resonators being capable of being excited under different circumstances. Chance seems to have led to the resonator characterised by the sediments at Schofield Street being excited by this particular earthquake.

In order to more fully understand the seismic response of the Hutt Valley sediments a crown-funded project to acquire more SCPT data from the area was commenced. Four sites in addition to the Schofield St one were probed, and the plan was to extend this work to both the north and the west. However, it was drawn to our attention that probing deeper than $8 \mathrm{~m}$ contravenes a bylaw, because it risks the integrity of the aquifer which is a source of unpolluted water. The provisions for legally probing below $8 \mathrm{~m}$ make this simple, cost-effective process both complicated and expensive, so the work was discontinued. Nevertheless it is appropriate to describe the work already completed.

Figs. 33 to 37 show the complete SCPT results for the five lower Hutt Valley sites. The McEwan park and Miro St probes (Figs. 33 and 37) were undertaken within a few metres of the original sites (Figs. 21 and 27) but were extended to the impenetrable gravels. Thus they offer a check on the repeatability of the CPT measurements. The Shandon Golf Course site (Fig. 35) is well removed from the earlier CPT site and the results are thus not directly comparable.

In terms of the CPT results, the five new probes show that there is a layer, roughly ten metres thick, of relatively coarse grained material, over a wedge of fine grained material in the lower part of the Hutt Valley. The layer corresponds to Taita alluvium and the wedge, which tapers up valley vanishing about Waterloo, corresponds to Petone marine clay and silt beds. This wedge may well be thicker nearer the western side of the valley, a result of the ongoing tectonic tilting which both forces the Hutt river to the western side of the valley and results in a wedge shape for all the alluvial fill of the valley.

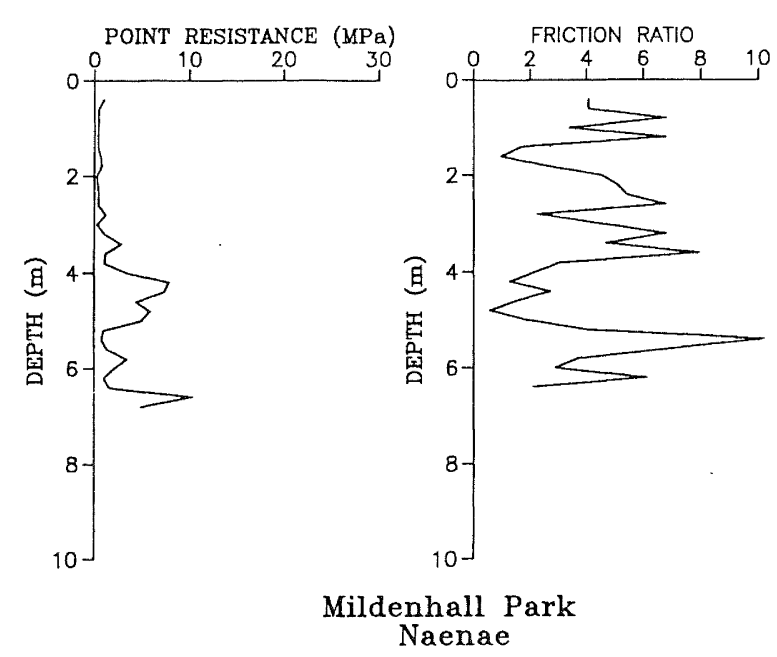

Fig. 32. Values of tip resistance and friction ratio as functions of depth at Walter Mildenhall Park, lower Hutt Valley (site 3J).

In terms of the shear wave velocities, the layer and wedge are remarkably similar, becoming marginally stiffer in an up valley direction. Values are $163 \mathrm{~m} / \mathrm{s}$ at McEwan park (Fig. 33), $175 \mathrm{~m} / \mathrm{s}$ at Schofield St (Fig. 34), $172 \mathrm{~m} / \mathrm{s}$ at Shandon Golf Course (Fig. 35), $188 \mathrm{~m} / \mathrm{s}$ at Te Mome stream (Fig. 36) and $190 \mathrm{~m} / \mathrm{s}$ at Miro St Fig. 37). Shandon Golf Course and Te Mome stream each appear to have a roughly $2 \mathrm{~m}$ thick superficial layer with a velocity of around $100 \mathrm{~m} / \mathrm{s}$, presumably due to local recent swamp or stream deposits.

The lower reaches of the Hutt Valley are wide, perhaps corresponding more to a plain than a basin, with the Hutt river constituting a mechanical boundary slanting across the valley, and with ongoing tectonic processes probably allowing a much deeper accumulation of recent sediment along the western valley margin. As well as tending more to the characteristics of a plain than a basin, the thin (about $30 \mathrm{~m}$ ) recent sediments of the valley are underlain by up to $300 \mathrm{~m}$ of older, presumably stiffer, sediments. The shear wave properties and dynamic role of these are unknown. Even though gross damage is not normally associated with materials of their type, they may still play an important part in the response of the more flexible material, perhaps by enabling the potential of surface waves. Much more work regarding shear wave characterisation and earthquake recording will be needed before the Hutt Valley system can be considered solved.

\section{EASTERN BAYS}

It was thought that there might be deposits of soft sediments along the eastern bays of Wellington Harbour. To substantiate this view cone penetration tests (CPT) were carried out at likely locations in Eastbourne (at Shortt Recreation Ground, Muritai School and Bishop Park), Days Bay (Williams Park) and Lowry Bay (Cheviot Street). There were no significant layers of soft or weak materials at any of these sites below about $3 \mathrm{~m}$ depth. At Shortt Recreation Ground there is a $0.5 \mathrm{~m}$ thick layer of loose sand from about $1.5 \mathrm{~m}$. At Bishop Park there is a thin layer of loose sand at about $1 \mathrm{~m}$ depth. At Lowry Bay there is approximately a $1 \mathrm{~m}$ thick layer of soft clayey sandy silt from about $2 \mathrm{~m}$ depth. At all sites (except Bishop Park) the probes reached refusal in dense sand or gravelly sand, while at Bishop Park probing was stopped in very stiff clayey sandy sand. The Eastern Bays results are not shown graphically but the locations are shown in Fig. 5, and the grid references given in Table 4. 


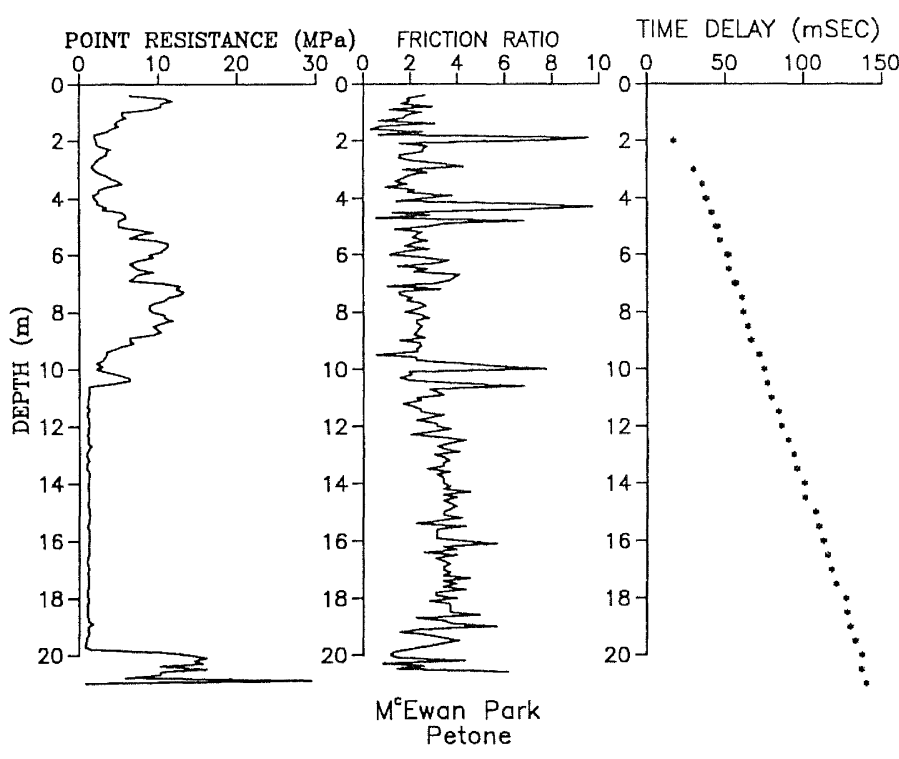

Fig. 33. Values of tip resistance, friction ratio and shear wave arrival time as functions of depth at McEwan Park, lower Hutt Valley (site 3K).

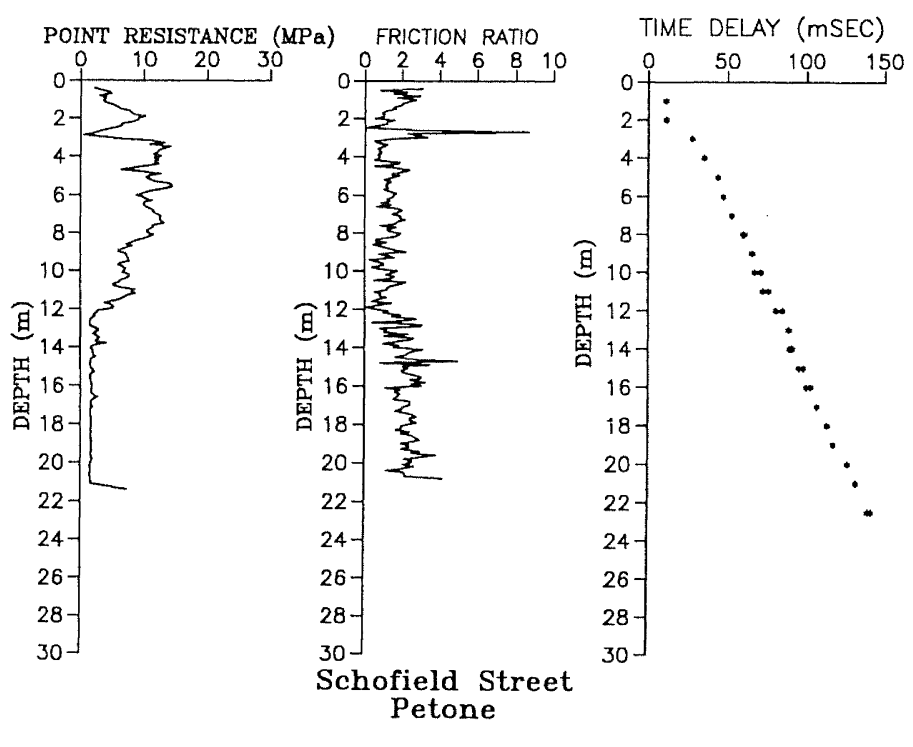

Fig. 34. Values of tip resistance, friction ratio and shear wave arrival time as functions of depth at Schofield St play area, lower Hutt Valley ( site 3B).

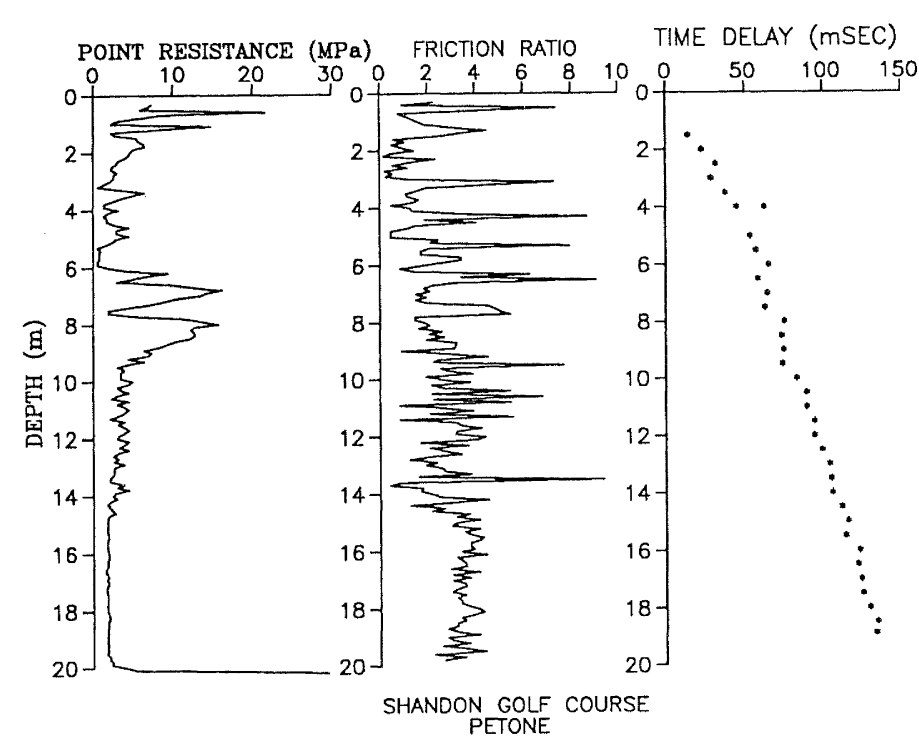

Fig. 35. Values of tip resistance, friction ratio and shear wave arrival time as functions of depth at Shandon Golf Course, lower Hutt Valley (site 3L).

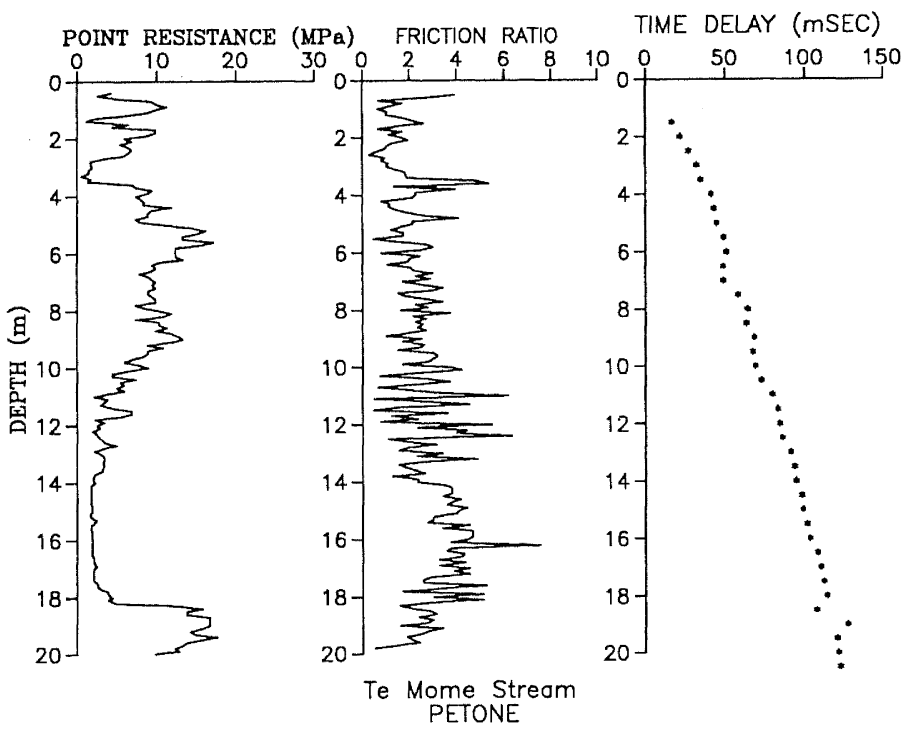

Fig. 36. Values of tip resistance, friction ratio and shear wave arrival time as functions of depth at $\mathrm{Te}$ Mome Stream, lower Hutt Valley (site 3M). 


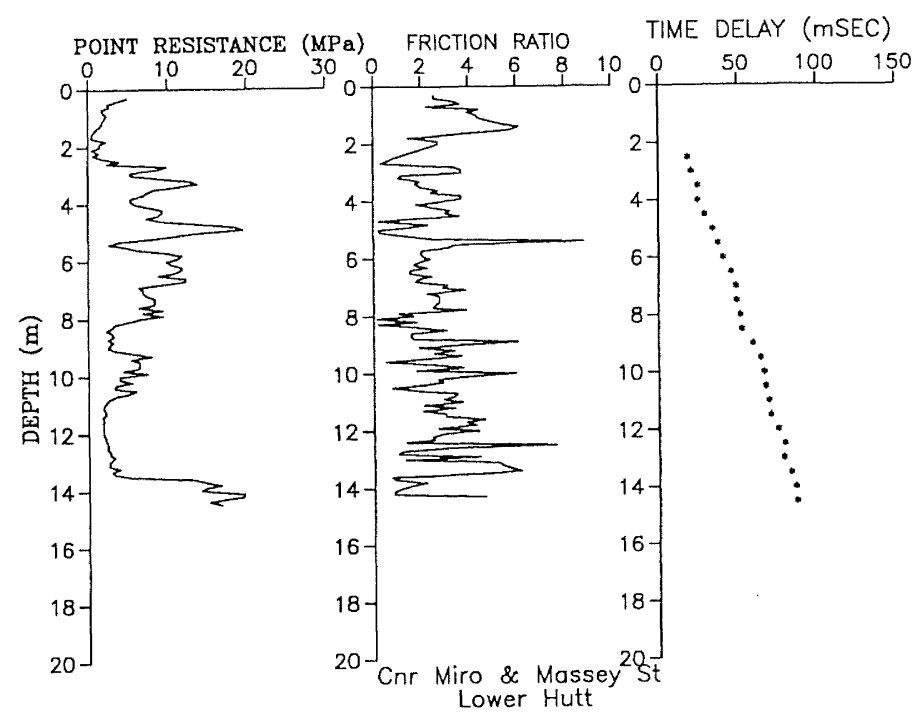

Fig. 37. Values of tip resistance, friction ratio and shear wave arrival time as functions of depth at corner of Miro St and Massey St, lower Hutt Valley (site 3E).

\section{STOKES VALLEY}

It was thought possible that Stokes Valley might have deposits similar to Wainuiomata, although the slope of Stokes Valley is sufficiently steep that fine grained materials may well have been flushed downstream. To check on the situation two CPT tests were carried out at likely locations, Delaney Park and behind the Kindergarten on Main Road. At Delaney Park there is about $2 \mathrm{~m}$ of soft silty sand (between 1 and $3 \mathrm{~m}$ ) underlain by gravels and moderately dense sand. Further down the valley at the kindergarten there is about $2 \mathrm{~m}$ of soft clayey silt overlying moderately dense gravelly sand at about $3 \mathrm{~m}$. The Stokes Valley results are not shown graphically but the locations are shown in Fig. 5, and the grid references given in Table 5.

\section{EXPECTED BUILDING DAMAGE}

Most large buildings in New Zealand are designed and built to comply with the NZS 4203 standard as economically as possible. The usual consequence of this is for buildings to have natural periods proportional to their heights. In round terms the period of a reinforced concrete structure is likely to be 0.1 seconds times the number of stories. On flexible soils foundation compliance can increase this value.
When responding resonantly to an earthquake, a building will exhibit a low damping, and will only respond strongly to excitation near its natural period. If the natural periods of the building and the ground differ by more than $25 \%$ it is expected that the building will be subjected to loads of less than twice those experienced by completely detuned buildings.

The extent to which ground resonances will be excited during earthquakes depends on the size and distance of the earthquake, with an extreme case involving a large distant shallow event, greater than magnitude six and more than fifty kilometres distant. In such a case the rock-borne incident waves will have an abundance of low frequency energy suitable to excite the resonator, and will have an extended duration. Buildings on this ground will experience prolonged strong shaking in such an earthquake. In terms of Modified Mercalli intensity (MM) the increase in shaking effects caused by the sediment amplifying such a large distant earthquake will be up to IV on the MM scale [21]. Thus an earthquake similar to the 1942 June 24 Wairarapa event would be expected to give rise to an intensity of MM IX for the flexible deposits which have been given a microzone rating of five, but only $\mathrm{MM} \mathrm{V}$ on bedrock in the same area. There are insufficient records of the 1942 event to verify that such increases occurred then.

The increase in damage attributable to flexible sediments would be smaller for a local event. Much of the shaking in such an event would be at frequencies which the flexible sediment would not amplify and could even diminish. In such a case, say an earthquake of magnitude 7.5 with its source $15 \mathrm{~km}$ from the sediments, an increase of 2 on the MM scale could be expected due to the sediments [21]. This would be coupled with a higher innate variability of the intensity because the source would subtend a considerable angle and the high frequency waves would interfere both destructively and constructively. In addition focusing effects and topographic amplification would give rise to varying intensities. A rock intensity of between VIII and IX would be converted to a sediment intensity of between $X$ and XI by soil effects alone. With the cost of repairs to lifelines (electricity, gas, telephone, sewers) going up by a factor of ten for each step on the MM scale [5], these figures have important planning consequences.

Dramatic though the previous estimates of increased damage are, they do not constitute the maximum effect of resonant sediment. The maximum effect occurs when a large distant earthquake excites a building whose natural period is the same as the natural period of the flexible sediment on which the building is founded. In such a case the building is excited with a long duration train of motion at its resonant period, and responds accordingly. It becomes meaningless to state factors

\begin{tabular}{|c|c|c|}
\hline SITE & & NZMG REFERENCE \\
\hline Shortt Recreation Ground & $4 \mathrm{~A}$ & NZMS 260 R27 686882 \\
\hline Muritai School & 4B & NZMS 260 R27 687885 \\
\hline Bishop Park & $4 \mathrm{C}$ & NZMS 260 R27 690892 \\
\hline Williams Park & $4 \mathrm{D}$ & NZMS 260 R27 697900 \\
\hline Cheviot St & $4 \mathrm{E}$ & NZMS 260 R27 704927 \\
\hline
\end{tabular}

Table 4. Locations of penetrometer sites, Eastern Bays. 
by which loadings increase in these circumstances except for brittle structures. This is because well-designed structures will behave in a ductile fashion when pushed beyond the linear range. Ductility limits the induced forces but this can be at the expense of structural integrity. Ductile action means that energy is being absorbed by the structure and the consequences of this depend upon structural detailing. The number of cycles of strong motion experienced by structures in the 1985 Mexico earthquake (those on the clays of Mexico City) suggests that it would be best not to rely on ductility to carry structures founded on flexible sediment through a large shallow distant earthquake. At the very least any structure whose natural period coincides with that of the ground should be designed to resist input motion which has been amplified by a resonator having the natural period of the ground and $5 \%$ of critical damping. Using the approximation that the period is about 0.1 seconds times the number of stories, structures around ten stories in height at Wainuiomata, four stories in height at Porirua, and seven stories in the lower Hutt Valley, should have such special design. In the Hutt Valley case it is assumed that all sediment effects originate in the top very flexible 20 to 30 metres of sediment. However the Hutt Valley situation is complex and many natural modes are expected due to the extent and shape of the valley. Although the shear wave properties of the 300 metres of older, coarser sediment above bedrock are completely unknown, they could have a significant response even though microzone amplification is more usually associated with near surface material.

It is not a sufficient defence to ensure that buildings co-resonant with the ground are founded on piles driven to firm material below the flexible sediment, because the forces involved are horizontal, and piles can deform so that the building basement moves with the soil surface.

By far the best response to the existence of the resonant regions identified in this paper is to prevent the erection within these regions of buildings in the sensitive period range. Either much stiffer or much more flexible structures would be acceptable. If a given architectural design leads to a co-resonant structure it is worth remembering that stiffening techniques generally yield increased strength, so a decrease in design natural period is preferable to an increase.

A limitation of this study is our ignorance of what fraction of earthquakes have the spectral character necessary to cause extreme variations in building shaking by means of ground resonance. It is only known that large distant earthquakes will do so. However the results from Caracas (1967), Manila (1967 and 1970), Mexico City (1985) and San Francisco (1989) suggest that such earthquakes are not uncommon.

In general the earthquake provisions of the New Zealand structural design code are excellent, and there is no concern that flexible soils may lead to catastrophic collapses with great loss of life. In particular, the traditional wooden framed house, provided that it has a light weight roof and chimney, and a continuous foundation wall, will perform well during earthquakes. However there is no avoiding the fact that deep flexible soils, such as those found by this study in Wainuiomata, Porirua, Naenae and the lower part of the Hutt Valley, will be associated with more damage during, and higher repair costs after, a large distant earthquake. This hazard can be minimised by not constructing buildings which are co-resonant with the soil.

\section{MODELLING STUDIES}

Central to the idea of studying the resonant response of soils is the concept of resonant modes [14], [17], [22] in which units of soil have coherent motion over a wide area. This concept rejects the once-popular philosophy under which the local resonant response at a point would involve the shear wave velocity and depth at that point. Under this old philosophy different parts of a small basin would have different natural periods. Instead, it is recognised that the properties of all sites within an area of one rock wavelength diameter will contribute to the unique natural period of the whole area. In the case of Porirua we may take a rough period of 0.4 second and a shear wave velocity in the rock of 4000 metres per second, to deduce a dimension of $1600 \mathrm{~m}$ over which the soil properties should be combined. This argument leads to the adoption of a single resonant period for the area of flexible sediment in the Porirua basin, because it is only of the order of $600 \mathrm{~m}$ across.

Any model adopted to combine the sediment velocities and depths should reflect the easily-sheared but incompressible dynamic nature of the sediments (as expressed by a low shear wave velocity but a high compressional wave velocity). Furthermore it should incorporate the frequent observation that on flexible soils the horizontal component of ground motion is many times greater than the vertical component.

A simple model which complies with these restrictions is axisymmetric about a vertical axis and has horizontal tangential resonant motion. Several such models have been constructed for the Porirua basin [18] and evaluated using the Finite Element Method. One such model is shown in Fig. 38 by way of example. All models (except the infinite plane layer one) have a maximum diameter of $600 \mathrm{~m}$, the width of the Porirua inlet.

From the model results it was seen that the natural period varies little with changes of shear wave velocity towards the periphery, but is more sensitive to variations in the basement profile, being principally controlled by the shear wave velocity profile at the deepest point.

\section{IDENTIFYING BOUNDARIES}

It is thought that at the boundary between flexible and stiff material, the motion will be that of the stiff material, and that the flexible ground effect will have a progressive onset moving away from the boundary. The scale of this onset is unknown. It relates to the mode shape of the resonant mode, which in turn is controlled by the boundary slope among other things. It is conceivable that modes other than the simple ones considered in this paper could be excited. The only conservative assumption which can be made about the spacial onset of resonant motion is that it has a scale of a quarter shear wavelength in the flexible material.

Even with this conservative approach it must be realised that many factors are not absolutely clear. As mentioned earlier, resonant effects may extend well into the stiffer bounding material in certain circumstances. 


\begin{tabular}{|lc|c|}
\hline \multicolumn{2}{|c|}{ SITE } & NZMG REFERENCE \\
\hline Delaney Park & 5A & NZMS 260 R27 761012 \\
\hline Kindergarten & 5B & NZMS 260 R27 764027 \\
\hline
\end{tabular}

Table 5. Locations of penetrometer sites, Stokes Valley.

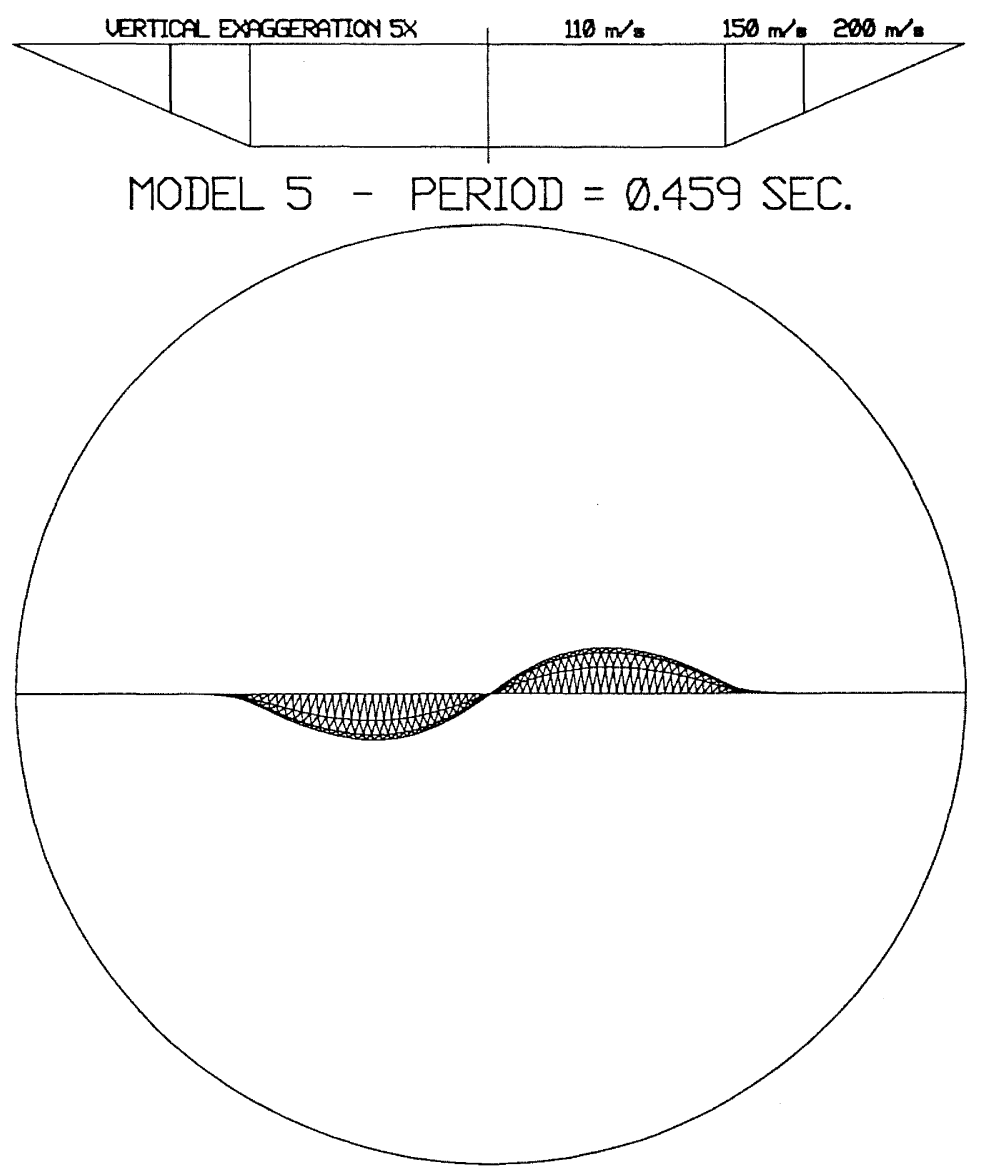

Fig. 38.

Fundamental axisymmetric mode of a basin intended to crudely model the Porirua harbour. Top - elevation, bottom - plan. Modelling used the finite element method, basin diameter was $600 \mathrm{~m}$, and basin depth $12 \mathrm{~m}$.

\section{CONCLUSIONS}

Use of the seismic CPT probe is a cost effective way of assessing resonant frequencies for recent fine grained sediments which have no impenetrable obstacles. However for the most reliable results it should be combined with small earthquake measurements, the two methods serving to check one another and warn of misunderstood circumstances.

\section{ACKNOWLEDGEMENTS}

We are grateful to Wellington Regional Council in the person of Dr Wayne Hastie for financially supporting the Wainuiomata and Porirua investigations and for consenting to the publication here of some of the results. 


\section{REFERENCES}

1. Chang, C.-Y., Mok, C.M., Power, M.S., Tang, Y.K. and Stepp, J.C. 1991, "Development of shear modulus reduction curves based on Lotung downhole ground motion data". Proceedings: Second International Conference on Recent Advances in Geotechnical Earthquake Engineering and Soil Dynamics, St Louis, U.S.A. 1: 111-118.

2. Dellow,G.D., Read,S.A.L., Begg,J.G., Van Dissen,R.J., Perrin,N.D 1992, "Distribution of geological materials in Lower Hutt, and Porirua, New Zealand: a component of a ground shaking hazard assessment", Bulletin of the New Zealand National Society for Earthquake Engineering (this volume).

3. Gale,S.J. 1992, "Regolith: The mantle of unconsolidated material at the earth's surface", Quaternary Research 37, 261-262.

4. McVerry, G.H. 1992, Personal communication.

5. O'Rourke, T.D., Stewart, H.E., Gowdy, T.E. and Pease, J.W. 1991, "Lifeline and geotechnical aspects of the 1989 Loma Prieta Earthquake", In Proceedings, Second International Conference on Recent Advances in Geotechnical Earthquake Engineering and Soil Dynamics, St. Louis. Vol.2 p1601.

6. Pender, M.J. and Larkin,T.J. 1991, "Effect of strain dependent stiffness and damping on site amplification", In Proceedings, Pacific Conference on Earthquake Engineering. Auckland, New Zealand: Vol.3.p.159.

7. Robertson, P.K., Campanella, R.G., Gillespie, D. and Rice, A. 1986, "Seismic CPT to measure in-situ shear, wave velocity", Journal of Geotechnical Engineering 112(8): 791-803.

8. Sanglerat, G. 1972, "The penetrometer and soil exploration", Elsevier, Amsterdam.

9. Searle, I.W. 1979, "The interpretation of Begemann friction jacket cone results to give soil types and design parameters", Proceedings: Seventh European Conference on Soil Mechanics and Foundation Engineering. Brighton 2: 265-270

10. Seed, H.B., Romo, M.P., Sun, H., Jaime, A. and Lysmer, J. 1985, "Relationships between soil conditions and earthquake ground motions in Mexico City in the earthquake of September 19, 1985", Earthquake Engineering Research Center. Report No. UCB/EERC $-87 / 15$. Berkeley.

11. Seed, H.B. and Sun, J. 1989, "Implications of site effects in the Mexico City earthquake of September 19 1985 for earthquake-resistant design criteria in the San Francisco Bay area of California", Earthquake Engineering Research Center. Report No. UCB/EERC$89 / 83$. Berkeley.

12. Sezawa, K. and Kanai, K. 1935, "Decay constants of seismic vibrations of a surface layer", Bulletin of the Earthquake Research Institute 13: 251-265.
13. Sritharan, S. and McVerry, G.H. 1992, "Microzone effects in the Hutt Valley in records from a strongmotion accelerograph array", Bulletin of the New Zealand National Society for Earthquake Engineering (this volume).

14. Stephenson, W.R. 1974, "An experimental study of normal modes of vibration of saturated alluvium", Proceedings, Fifth Symposium on Earthquake Engineering, Roorkee, November 9-11.

15. Stephenson, W.R. 1975, "Cellular normal modes of alluvium response", Bulletin of the New Zealand National Society for Earthquake Engineering 8(4): 245-254

16. Stephenson, W.R. 1989, "Normal modes of a "cylindrical valley' of alluvium", Bulletin of the New Zealand National Society for Earthquake Engineering 22(2): 76-80.

17. Stephenson, W.R. 1989, "Observation of a directed resonance in soil driven by transverse rock motion", Bulletin of the New Zealand National Society for Earthquake Engineering 22(2): 81-89.

18. Stephenson, W.R. 1990, "EIGAXI.PAS - A computer program to quantify the shear resonance of axisymmetric basins of soft soil", DSIR Land Resources Technical Record 17, Department of Scientific and Industrial Research, Lower Hutt, New Zealand.

19. Stephenson, W.R. and Barker, P.R. 1989, "Seismic response of soil materials around Edgecumbe, Bay of Plenty, New Zealand", New Zealand Journal of Geology and Geophysics Vol. 32: 175-180.

20. Stephenson, W.R. and Barker, P.R. 1991, "Results from the Pukehou array", In Proceedings, Pacific Conference on Earthquake Engineering. Auckland, New Zealand: Vol.3.p.229.

21. Stephenson, W.R. 1991, "An assessment of the proportion of earthquakes likely to be amplified by flexible sediments", In Proceedings, Pacific Conference on Earthquake Engineering. Auckland, New Zealand: Vol.3.p.149.

22. Stephenson, W.R. 1991, "Cellular Normal Modes: An Explanation for Alluvium Response to Earthquakes", In Proceedings, Second International Conference on Recent Advances in Geotechnical Earthquake Engineering and Soil Dynamics, St. Louis, Missouri, pp 1155-1165.

23. Taber, J.J. and Smith, E.G.C. 1992, "Frequency dependent amplification of weak ground motions in Porirua and Lower Hutt", Bulletin of the New Zealand National Society for Earthquake Engineering (this volume)

24. Van Dissen,R.J., Taber,J.J., Stephenson,W.R., Sritharan,S., Read, S.A.L., McVerry, G.H., Dellow, G.D, and Barker,P.R. 1992, "Ground shaking hazard assessment for the Lower Hutt and Porirua areas, New Zealand", Bulletin of the New Zealand National Society for Earthquake Engineering (this volume). 